\title{
1 Latent gammaherpesvirus exacerbates arthritis and requires age-associated B cells
}

3 Isobel C. Mouat ${ }^{1}$, Zach J. Morse ${ }^{1}$, Iryna Shanina ${ }^{1}$, Kelly L. Brown ${ }^{2}$, and Marc S. Horwitz ${ }^{1}$

5 'Department of Microbiology and Immunology, The University of British Columbia, Vancouver,

6 British Columbia, Canada

$7 \quad{ }^{2}$ Department of Pediatrics, Division of Rheumatology, and British Columbia Children's Hospital

8 Research Institute, The University of British Columbia, Vancouver, British Columbia, Canada

9

10 Corresponding author:

11 Marc S. Horwitz

12 Room 3551, Life Sciences Centre

$13 \quad 2350$ Health Sciences Mall

14 University of British Columbia

15 Vancouver, B. C. Canada V6T $1 Z 3$

$16 \quad 604-822-6298$

17 mhorwitz@mail.ubc.ca 


\section{Abstract}

21 Epstein-Barr virus (EBV) infection is associated with rheumatoid arthritis (RA) in adults, though

22 the nature of the relationship remains unknown. Herein, we examine the contribution of viral

23 infection to the severity of arthritis in mice. We provide the first evidence that latent

24 gammaherpesvirus infection enhances clinical arthritis, modeling EBV's role in RA. Mice latently

25 infected with a murine analog of EBV, gammaherpesvirus 68 ( $\gamma \mathrm{HV} 68)$, develop more severe

26 collagen-induced arthritis and a Th1-skewed immune profile reminiscent of human disease. We

27 demonstrate that disease enhancement requires viral latency and is not due to active virus

28 stimulation of the immune response. Age-associated B cells ( $A B C$ s) are associated with several

29 human autoimmune diseases, including arthritis, though their contribution to disease is not

30 well understood. Using $A B C$ knockout mice, we provide the first evidence that $A B C s$ are

31 mechanistically required for viral enhancement of disease, thereby establishing that latent

32 gammaherpesvirus infection stimulates $A B C$ s to provoke arthritis.

33

\section{Conflict of interest statement}

35 The authors have declared that no conflict of interest exists. 
Introduction

39 Rheumatoid arthritis (RA) is one of the most common autoimmune diseases in adults, though

40 the etiology and pathophysiology are not fully understood(1,2). RA, as well as other

41 autoimmune diseases including multiple sclerosis and systemic lupus erythematosus, is

42 associated with Epstein-Barr virus (EBV) infection(3-5). The circulating EBV load is higher in

43 individuals with RA than otherwise healthy adults(3) and RA patients have increased levels of

44 antibodies specific to multiple EBV-encoded proteins(6-10). Further, RA patients have

45 increased EBV-specific CD8 ${ }^{+}$T cells(11) yet these cells have a reduced ability to kill EBV-infected

46 B cells when compared to the same subset of EBV-specific CD8 ${ }^{+} T$ cells from healthy

47 controls(12). However, the precise role of EBV in RA pathogenesis remains unknown. EBV

48 infection typically takes place during childhood or adolescence, while RA generally becomes

49 symptomatic during middle age, indicating that the latent EBV infection likely modulates the

50 immune system over time in a manner that contributes to the development of RA $(1,13-15)$.

52 Evidence from in vivo models are scarce and previous studies have focused primarily on the

53 direct relationship between EBV infection and damage to the joint capsule, with little attention

54 given to systemic effects of EBV infection on immune modulation preceding and continuing

55 throughout disease. Mice with humanized immune systems, namely NOD/Shi-scid/IL-

$562 \mathrm{R} \gamma^{\text {null }}$ mice reconstituted with $\mathrm{CD}_{3} 4^{+}$hematopoietic stem cells, that were infected with EBV

57 went on to spontaneously develop erosive arthritis, suggesting a causative role of EBV in

58 arthritis development(16). Related, a serum transfer-induced arthritis model was used to

59 demonstrate that Ly $6 C^{\text {high }}$ monocytes play a role in transporting murine gammaherpesvirus 68 
60 ( $\gamma \mathrm{HV} 68)$, an EBV homolog, to the synovium(17). Our group has previously shown that latent

$61 \gamma \mathrm{HV} 68$ infection enhances experimental autoimmune encephalomyelitis (EAE) and leads to a

62 disease that more closely resembles multiple sclerosis (MS)(18). Critically, this enhancement

63 was specific to $\gamma \mathrm{HV} 68$; other viruses, including lymphocytic choriomeningitis virus (LCMV) and

64 murine cytomegalovirus (MCMV), did not lead to enhancement of EAE. Additionally,

65 enhancement took place without changes to autoantibody levels. An in vivo model that

66 recapitulates the temporal and systemic immunological aspects of the relationship between

$67 \quad$ EBV and RA is critical.

69 To examine the relationship between EBV and RA, we have adapted in vivo models of both.

$70 \gamma \mathrm{HV} 68$ is a natural pathogen that is a $\mathrm{HHV} 68$ well-established and widely-used murine model of

71 EBV infection that shares an array of characteristics with human EBV infection, including latent

72 persistence in B cells, a potent CD8 T cell response, and immune evasion tactics(19,20). Type II

73 collagen-induced arthritis (CIA) is a commonly used model of RA wherein mice are injected with

74 type II collagen emulsified in adjuvant. Here, we chose to use C57BI/6 mice due to the extensive

75 past characterization of $\gamma \mathrm{HV} 68$ infection in C57BI/6 mice and the numerous knockout strains

76 available on this background. Multiple strains of mice are susceptible to $\mathrm{ClA}$, including $\mathrm{C} 57 \mathrm{BI} / 6$

77 mice that, despite displaying a less severe disease course than other strains, generate a robust

78 T cell response. In C57BI/6 mice, ClA follows a chronic disease course with a sustained T cell

79 response, presence of anti-collagen $\lg G$, and infiltration of inflammatory lymphocytes into the

80 joint capsule(21). Here we show that C7BI/6 mice latently infected with $\gamma \mathrm{HV} 68$ and induced for

81 CIA develop a more severe clinical course and altered immunological profile, with an expansion 
82 of $\mathrm{CD}^{+} \mathrm{T}$ cells and Th1 skewing. We have utilized $\gamma \mathrm{HV} 68$ infection and CIA induction to

83 investigate the mechanism(s) by which EBV contributes to RA, in particular the contribution of

84 age-associated B cells.

85

86 The role of $B$ cells the contribution of EBV to RA is intriguing because B cells contribute

87 pathogenically to RA, and EBV infects B cells and alters the B cell profile(22,23). Age-associated

88 B cells $(A B C s)$ are a subset of $B$ cells that are of particular interest as they have been implicated

89 in both autoimmunity and viral infection. When compared to healthy adults, the relative

90 proportion and/or absolute circulating counts of $A B C$ s are elevated in RA patients, a subset of

91 individuals with MS, individuals with systemic lupus erythematosus (SLE), and a subset of

92 people with common variable immune deficiency that display autoimmune complications'(24-

93 31). ABCs are required for disease development in mouse models of SLE(32). Also, ABCs are

94 increased during viral infections in mice and/or humans including lymphocytic choriomeningitis

95 virus, $\gamma \mathrm{HV} 68$, vaccinia, HIV, hepatitis C virus, and influenza. ABCs display an array of functional

96 capacities, including the secretion of anti-viral or autoantibodies, initiation of germinal centres,

97 antigen presentation to T cells, and secretion of cytokines(33-36). It is yet to be examined

98 whether $A B C s$ play a role in viral contribution to autoimmunity. We find that $A B C$ knockout (KO)

99 mice are unable to develop the $\gamma \mathrm{HV} 68$-exacerbation of $\mathrm{CIA}$, and therefore act as a mediator

100 between viral infection and autoimmunity. 


\section{Results}

\section{Latent $\gamma \mathrm{HV} 68$ infection exacerbates the clinical course of $\mathrm{CIA}$}

104 The development of RA often occurs years after initial infection with EBV when the virus is

105 latent. To mimic this temporal relationship, we infected mice with $\gamma H$ V68, waited five weeks for

106 the lytic infection to clear and the virus to establish latency, and induced CIA. Clearance of the

107 acute virus and establishment of latency has previously been shown by plaque assay on spleens

108 collected 35 days post-infection(18,37). Following CIA induction, mice were assessed three

109 times per week for redness and swelling in the hind two paws (Figure 1 - figure supplement

110 1A), which informed a clinical score (5-point scale from 0-4) for each mouse. We observe that

$111 \mathrm{CIA}$ in latent $\gamma \mathrm{HV} 68$-infected mice (herein referred to as $\gamma \mathrm{HV} 68-\mathrm{ClA}$ mice) has a more severe

112 clinical course than uninfected mice (herein referred to as CIA mice), as evidenced by

113 consistently higher clinical scores at disease onset and over the following 8 weeks (Figure 1A;

114 fold change-1.4 at day 56 post-induction). $\gamma \mathrm{HV} 68$-CIA mice also develop onset of disease

115 symptoms an average of seven days earlier than CIA mice (Figure 1C). In agreement with other

116 research groups, male and female mice displayed similar clinical scores during $\mathrm{CIA}$ and we also

117 do not observe a sex difference in $\gamma \mathrm{HV} 68-\mathrm{ClA}$ mice (Figure 1 - figure supplement 1B). As

118 expected, latent $\gamma \mathrm{HV} 68$ infected mice (without CIA) did not display any signs of disease (Figure

119 1A-B). Titers of anti-type II collagen autoantibodies (total IgG, IgG1, and IgG2c) were elevated in

120 sera from mice with $\mathrm{CIA}$ compared to naïve mice without $\mathrm{CIA}$ yet were similar in mice with $\mathrm{CIA}$

121 regardless of infection (Figure 1 - figure supplement 1 C-E), in line with our previous finding

122 that latent $\gamma \mathrm{HV} 68$ infection enhances EAE without influencing autoantibody levels(18). These

123 data demonstrate that latent $\gamma \mathrm{HV} 68$ infection leads to earlier onset and more severe CIA, 
124 though the exacerbation is not due to higher titers of autoantibodies against type II collagen or

125 change in abundance of particular immunoglobulin isotypes.

A

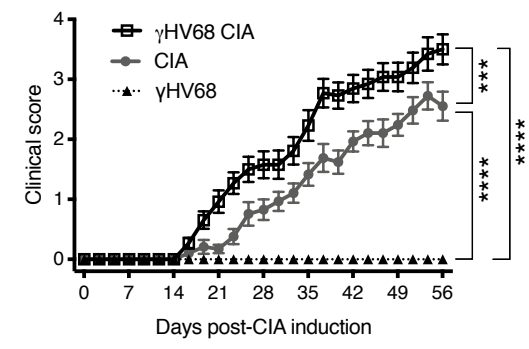

B

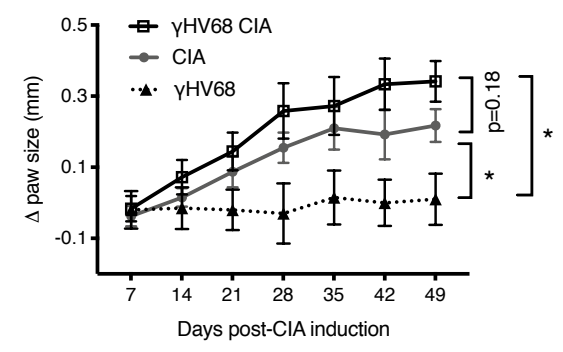

C

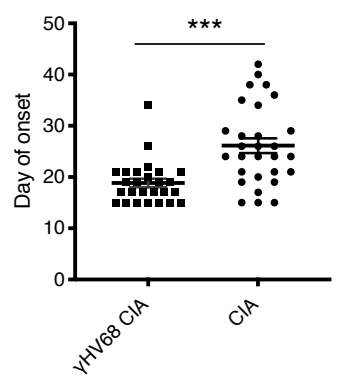

128 Figure 1: Progression of CIA in latent pHV68 infected and control uninfected mice. (A) Clinical

129 score (y-axis) of CIA measured three times weekly for 8 weeks (x-axis; days) post CIA induction

130 in mice without (CIA, filled circles) and with latent $\gamma \mathrm{HV} 68$ infection ( $\gamma \mathrm{HV} 68-\mathrm{CIA}$, open squares),

131 and starting at day 35 post-infection in mice infected with latent $p$ HV68 infection but not

132 induced for $\mathrm{CIA}$ ( $\gamma \mathrm{HV} 68$, filled triangles). (B) Change $(\Delta, y$-axis) in thickness of hind paws

133 measured with calipers once per week and averaged for each mouse. Began measuring $\mathrm{pHV68-}$

$134 \mathrm{CIA}$ and $\mathrm{ClA}$ the day of $\mathrm{ClA}$ induction, and $\mathrm{H} \mathrm{HV} 68$ at day 35 post-infection. (C) Day (y-axis) of $\mathrm{CIA}$

135 onset (considered two consecutive scoring days of a score of at least 1 ) in mice (x-axis) without

$136(\mathrm{ClA})$ and with latent $\mathrm{H} \mathrm{HV} 68$ infection ( $\gamma \mathrm{HV} 68-\mathrm{CIA})$. Each data point represents an individual

137 mouse. (A-C) Data presented as mean \pm SEM. Statistical significance determined by $(\mathbf{A}, \mathbf{B})$ two-

138 way ANOVA with Geisser-Greenhouse's correction, (C) t-test. *** $p<0.001, * * p<0.01,{ }^{*} p<0.05$.

139 (A) $n=10-29$ mice per group, 4 experiments; (B) $n=8-20$ mice per group, 3 experiments; (C)

140 n=26-29 mice per group, 4 experiments. 
142 The profile of immune cells infiltrating the synovium is altered in $\gamma \mathrm{HV} 68-\mathrm{CIA}$

143 To assess the types and relative proportions of immune cells infiltrating the joint synovium,

144 synovial fluid cells were collected on day 56 post-CIA induction. Synovial cells were collected

145 from the knee and ankle joints by flushing each joint with PBS and subsequently analyzing

146 isolated cells by flow cytometry. Synovial cells were not collected from naïve or $\gamma H V 68$-infected

147 mice without CIA because we would not expect there to be sufficient infiltration of immune

148 cells for analysis. The number of $\mathrm{CD}^{+} \mathrm{T}$ cells infiltrating the synovium during $\gamma \mathrm{HV} 68-\mathrm{CIA}$ is

149 increased compared to $\mathrm{CIA}$ (3.6-fold change), while there is no significant difference in the

150 number of $\mathrm{CD}^{+} \mathrm{T}$ cells (Figure $2 \mathrm{~A}$ ). Additionally, the $\mathrm{CD}^{+}$and $\mathrm{CD} 4^{+} \mathrm{T}$ cells in $\gamma \mathrm{HV} 68-\mathrm{CIA}$

151 synovium display a significant increase in Tbet expression compared to those in CIA (Figure 2B),

152 indicating Th1 skewing.

154 As further evidence that infiltrated T cells are immunologically active, we used RT-qPCR to

155 evaluate the expression of key T cell derived cytokines IFN $\gamma$ and IL17. The relative expression of

156 IFN $\gamma$ in synovium cells of $\gamma \mathrm{HV} 68-\mathrm{CIA}$ mice compared to CIA-mice was increased (fold chage-129),

157 while the relative expression of IL-17A is trending down in infected mice (Figure 2 C; fold

158 change-3.8). Together, these results indicate that IFN $\gamma$-producing T cells are preferentially

159 infiltrating the synovium in our model of $\gamma \mathrm{HV} 68-\mathrm{CIA}$, which is consistent with what is observed

160 in the synovium of RA patients(38). Our data also demonstrate a skewing towards cytotoxic

$161 \mathrm{CD}^{+} \mathrm{T}$ cells in mice latently infected with $\gamma \mathrm{HV} 68$ prior to $\mathrm{CIA}$. 
A

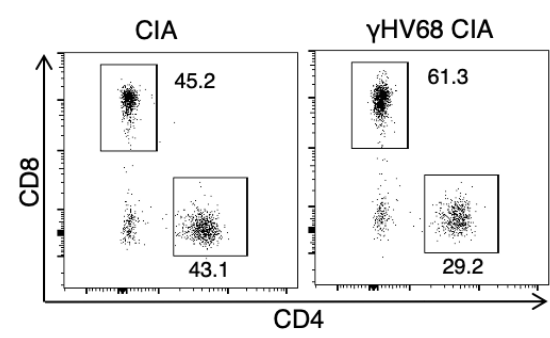

163
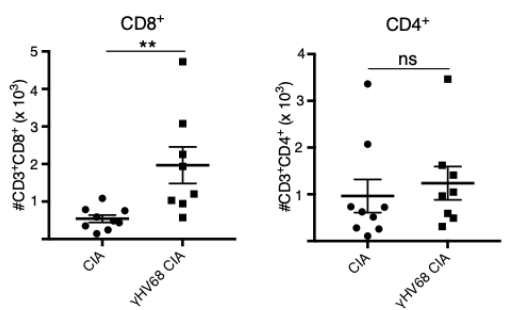

B

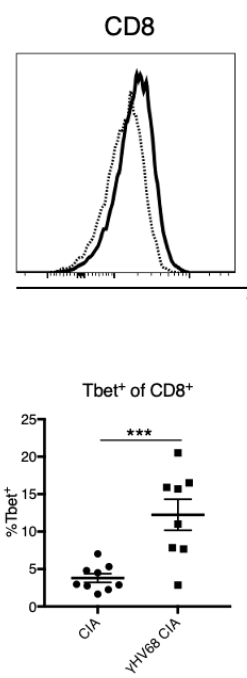

Synovium

CD4
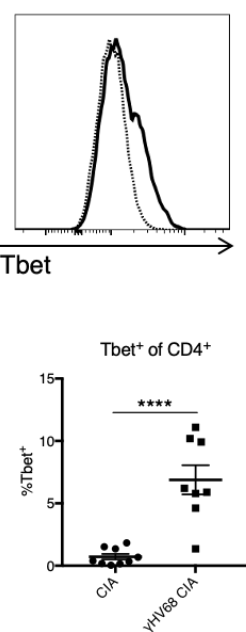

C Synovium
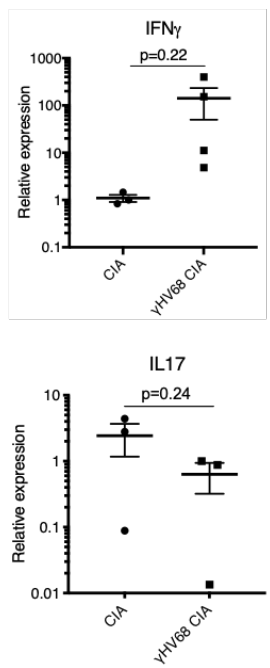

Figure 2: Analysis of immune infiltration to synovium between $\mathrm{yHV68-CIA}$ and control $\mathrm{CIA}$

mice at day 56 post-CIA induction. (A) Representative flow cytometry plots of synovial fluid

169 (x-axis) by $\mathrm{CD}^{+}$or $\mathrm{CD}^{+} \mathrm{T}$ cells in CIA mice (dotted line) and $\mathrm{\gamma HV68-CIA}$ mice (solid line).

170 Samples previously gated on lymphocytes, singlets, live cells, and $\mathrm{CD} 45^{+} \mathrm{CD} 3^{+}$cells. Percent of

$171 \mathrm{CD}^{+}$and $\mathrm{CD}^{+}{ }^{+}$cells positive for Tbet ( $\mathrm{y}$-axis, gated on a full minus-one control) in uninfected

172 mice with $\mathrm{CIA}$ (filled circles) and $\mathrm{\gamma HV68-CIA}$ mice (filled squares). (C) RNA extracted from

173 synovial fluid cells, RT-qPCR performed for IFN $\gamma$ and IL17, and relative expression plotted for

174 uninfected mice with CIA (filled circles) and $\mathrm{yHV68-CIA} \mathrm{mice} \mathrm{(filled} \mathrm{squares).} \mathrm{(A-B)} \mathrm{Flow} \mathrm{plots}$

175 are concatenated samples from all $\mathrm{CIA}$ or $\mathrm{yHV68-CIA}$ samples from an individual experiment,

176 n=8-9 mice per group; (C) n=3-4 mice per group; $(\mathbf{A}-\mathbf{C})$ One experiment, data presented as mean

$177 \pm$ SEM, analyzed by t-test, $* * * * p<0.0001, * * * p<0.001, * * p<0.01, * p<0.05$ 
178 Latent $\gamma \mathrm{HV} 68$ infection skews the T cell response towards a pathogenic profile during $\mathrm{CIA}$

179 To examine how latent $\gamma \mathrm{HV} 68$ might contribute to $\mathrm{CIA}$, we specifically examined the systemic T

180 cell profile. It is known that latent $\gamma \mathrm{HV} 68$ infection expands cytotoxic T cells and reduces

181 Tregs(39). Both cell types play a role in CIA with cytotoxic T cells being crucial mediators of $\mathrm{CIA}$

182 while Tregs play a protective role $(40,41)$. We examined T cells in the spleen and inguinal lymph

183 nodes (ILNs), a draining lymph node in which we observe a significant increase in overall

184 abundance of immune cells during $\mathrm{CIA}$ (data not shown). $\gamma \mathrm{HV} 68-\mathrm{ClA}$ mice display a decrease in

185 relative proportion of FoxP3 ${ }^{+}$Tregs and an increase in relative proportion of $\mathrm{CD}^{+} \mathrm{T}$ cells in the

186 spleen compared to control CIA mice (Figure 3A-B, Figure 3 - figure supplement $\mathbf{1 A - B}$ ). This is

187 similar to what is observed in people with RA, as activated CD8 ${ }^{+} \mathrm{T}$ cells are increased and Tregs

188 are decreased in the circulation of RA patients compared to otherwise healthy people $(42,43)$. In

189 the ILNs of $\gamma \mathrm{HV} 68-\mathrm{CIA}$ mice, we observe a trend of decreased relative proportion of regulatory T

190 cells and also decreased $\mathrm{CD}^{+}$and $\mathrm{CD} 4^{+} \mathrm{T}$ cells relative proportions, indicating potential $\mathrm{T}$ cell

191 egress from the ILNs during disease (Figure 3A-B, Figure 3 - figure supplement 1D-F). We also

192 observe a significant increase in relative proportion of $\mathrm{CD} 11 \mathrm{c}^{+} \mathrm{CD} 8^{+} \mathrm{DCs}$ in $\gamma \mathrm{HV} 68-\mathrm{CIA}$ mice

193 compared to CIA (Figure 3 - figure supplement 1D-F). This data shows that the T cell profile of

$194 \gamma \mathrm{HV} 68-\mathrm{ClA}$ mice is skewed pathogenically, with decreased Tregs and increased cytotoxic T cells. 
A
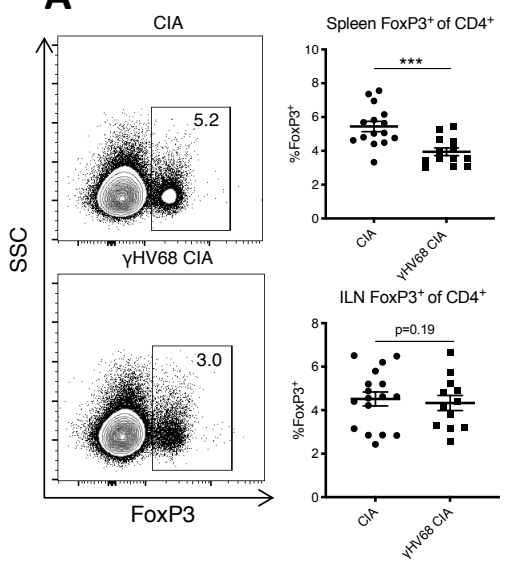

C ${ }_{\mathrm{CIA}}$
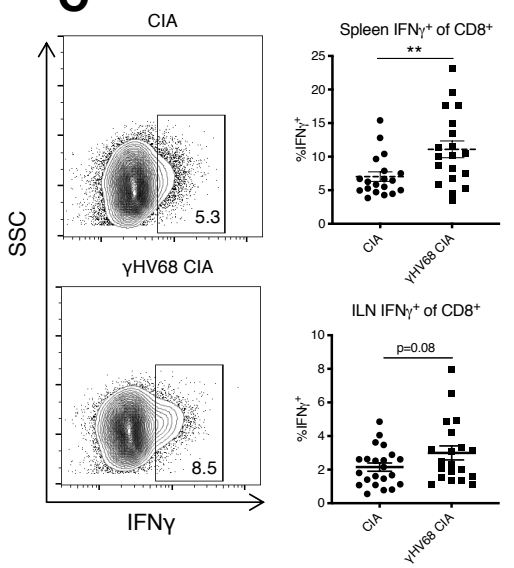
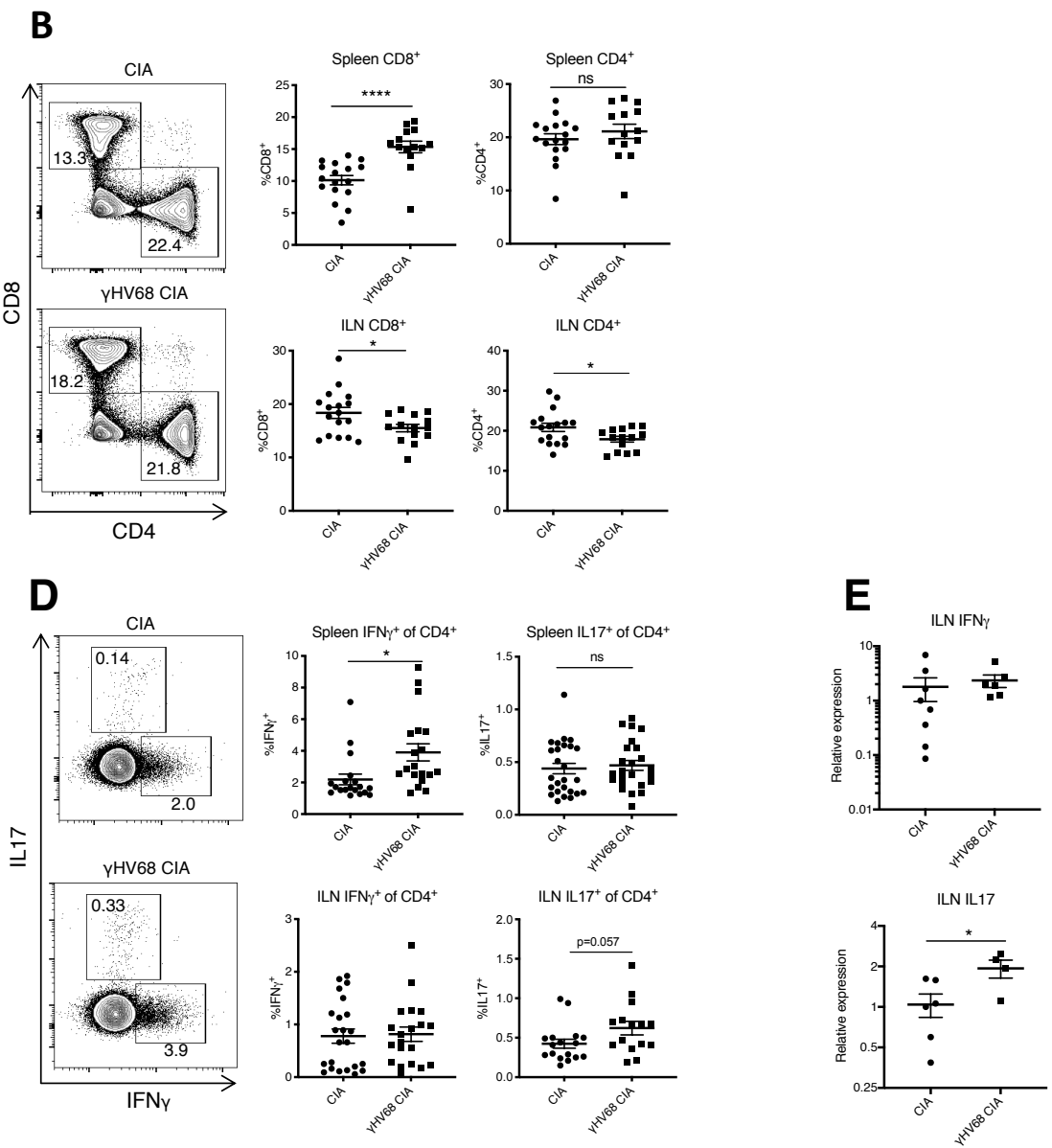

Figure 3: Flow cytometry analysis of spleen and ILN T cells at day 56 post-induction of pHV68-

CIA and control CIA mice. (A-D) Representative flow cytometry plots of spleen samples

previously gated on lymphocytes, live cells, singlets, $\mathrm{CD} 45^{+} \mathrm{CD} 3^{+}$cells, and (A, D) $\mathrm{CD} 4^{+}$cells, (C)

$199 \mathrm{CD}^{+}$cells, of uninfected mice with CIA (upper plot) and $\mathrm{HHV68-CIA} \mathrm{mice} \mathrm{(lower} \mathrm{plot).} \mathrm{(A,} \mathrm{C)}$

$\mathrm{CD}^{+}$; (B) $\% \mathrm{CD}^{+} \mathrm{CD}^{+}$and $\% \mathrm{CD}^{+} \mathrm{CD}^{+}$of $\mathrm{CD}^{+} 5^{+}$; (C) $\% \mathrm{IFN} \gamma^{+}$of $\mathrm{CD}^{+}$; (D) IFNy ${ }^{+}$or IL17 $7^{+}$of $\mathrm{CD}^{+}$; 
$\mathrm{n}=19-22$ mice per group, 3 experiments; (E) $\mathrm{n}=4-8$ mice per group, 1 experiment. (A-E) Each

data point represents an individual mouse. Data presented as mean $\pm \mathrm{SEM}$, analyzed by t-test,

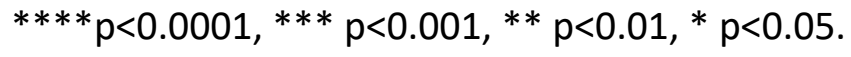

210 T cell polarization is modulated in $\gamma \mathrm{HV} 68-\mathrm{ClA}$ mice

211 Although IL17 has been highly studied due to its predominance in animal models of arthritis,

212 both IL17 and IFN $\gamma$ are involved in RA(38,43-45). As expected from our previous work with

$213 \gamma \mathrm{HV} 68-\mathrm{EAE}$, we find that in $\gamma \mathrm{HV} 68-\mathrm{ClA}$ greater numbers of splenic $\mathrm{CD}^{+}$and $\mathrm{CD} 4^{+} \mathrm{T}$ cells express

214 IFN $\gamma$ compared to CIA alone (Figure 3C-D). There is a maintenance of Th17 cells in the spleen,

215 with a similar proportion of $\mathrm{CD}^{+} \mathrm{T}$ cells expressing IL17 in $\mathrm{CIA}$ and $\gamma \mathrm{HV} 68-\mathrm{CIA}$ (Figure 3D). In the

216 ILNs, we observe a significant increase in IL17 by RT-qPCR (Figure 3E) and a corresponding trend

217 towards more IL17-expressing $\mathrm{CD}^{+} \mathrm{T}$ cells. We propose that the combined Th1 and Th17

218 profile observed in $\gamma \mathrm{HV} 68-\mathrm{ClA}$ is more reminiscent of what is observed in people with RA than

219 in $\mathrm{ClA}$ without $\gamma \mathrm{HV} 68$ infection.

221 Latency is required for the clinical and immunological $\gamma \mathrm{HV} 68$-exacerbation of $\mathrm{CIA}$

222 To examine the requirement of $\gamma \mathrm{HV} 68$ latency, as opposed to residual effects from acute

223 infection, for exacerbating CIA, we used a recombinant $\gamma \mathrm{HV} 68$ strain that does not develop

224 latency, ACRTA- $\gamma$ HV68. In ACRTA- $\gamma$ HV68 the genes responsible for latency are deleted and a

225 lytic gene, RTA, is constitutively expressed, resulting in clearance of the virus following acute

226 infection(46). We find that ACRTA- $\gamma$ HV68 infected mice do not develop the CIA clinical

227 enhancement that we observe in latently $\gamma H$ V68-infected mice, with the clinical course and day 
228 of onset resembling that of uninfected CIA mice (Figure 4A-B).

230 Furthermore, the immunological changes observed in $\gamma \mathrm{HV} 68-\mathrm{ClA}$ mice, when compared to $\mathrm{CIA}$

231 mice, are absent in ACRTA- $\gamma \mathrm{HV} 68 \mathrm{CIA}$ mice. The increase in relative proportion of CD8 ${ }^{+} \mathrm{T}$ cells in

232 the spleen is less pronounced in ACRTA- $\gamma \mathrm{HV} 68 \mathrm{CIA}$ compared to $\gamma \mathrm{HV} 68-\mathrm{CIA}$, while there is no

233 change in relative proportion of $\mathrm{CD}^{+} \mathrm{T}$ cells (Figure 4A-B). In ACRTA- $\gamma \mathrm{HV} 68 \mathrm{CIA}$ mice there is

234 abolishment of the $\gamma \mathrm{HV} 68$-induced upregulation of IFN $\gamma$ in $\mathrm{CD}^{+}$and $\mathrm{CD} 4^{+} \mathrm{T}$ cells, and no change

235 in IL17 expression by $\mathrm{CD}^{+} \mathrm{T}$ cells (Figure 4E-G). The decrease in relative proportion of splenic

236 Tregs and $\mathrm{CD}^{+}$infiltration into the synovial fluid observed in $\gamma \mathrm{HV} 68 \mathrm{CIA}$ mice is not present in

237 ACRTA- $\gamma \mathrm{HV} 68 \mathrm{CIA}$ mice (Figure 4H-I). Together, this data shows that ACRTA- $\gamma \mathrm{HV} 68 \mathrm{CIA}$ mice

238 display a similar clinical and immunological profile to uninfected CIA mice. This demonstrates

239 that the enhancement is not due to innate immune stimulation during the acute infection, but,

240 rather, the latency phase of $\gamma \mathrm{HV} 68$ infection is critical for the clinical and immunological

241 exacerbation of CIA. The requirement of $\gamma \mathrm{HV} 68$ latency mirrors the RA patient clinical course,

242 wherein patients are infected with EBV years before the onset of disease. 
A

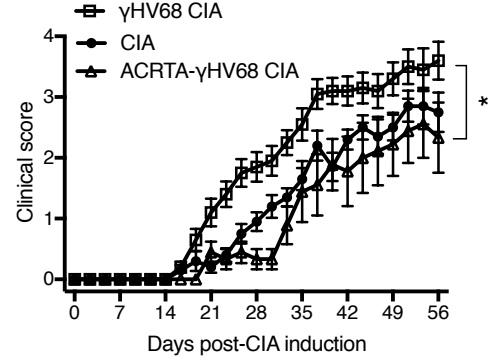

$\mathbf{E}$

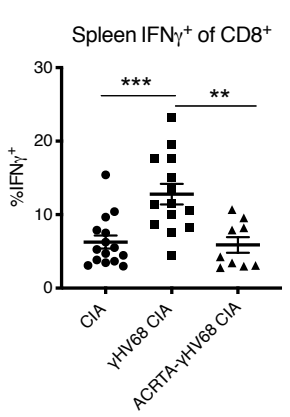

$\mathbf{F}$

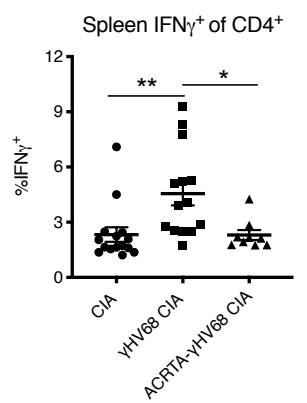

B

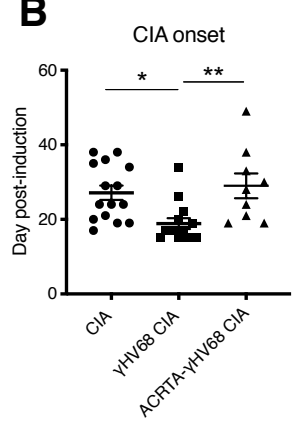

G

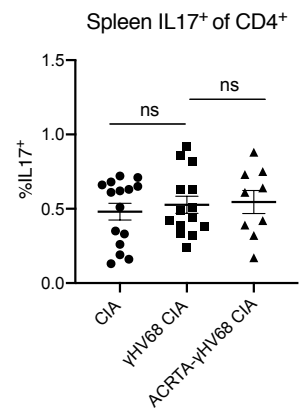

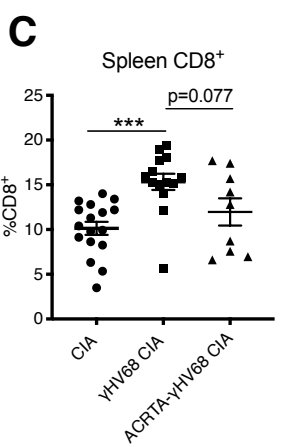

H

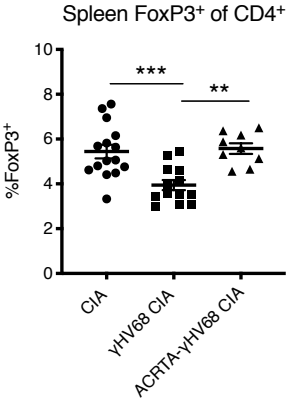

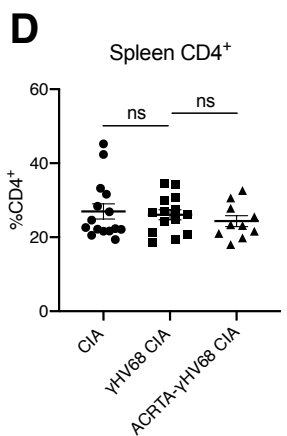

I

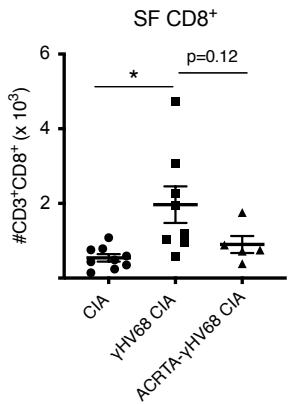

Figure 4: Disease progression and immune profile of latency-free ACRTA- $ү H$ V68 CIA mice

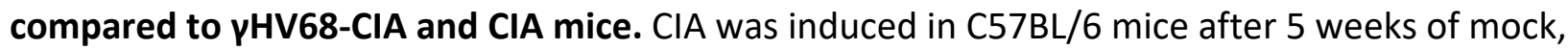

$247 \quad$ HV68, or ACRTA- $p H V 68$ infection, and mice scored for clinical disease until 56 days-post CIA

248 induction. At 56 days post CIA-induction, spleens and synovial fluid collected and processed for

249 flow cytometry. A proportion of the CIA and $\mathrm{HHV68-CIA}$ data is repeated from Figure 2. (A)

250 Clinical scores (y-axis) of uninfected mice with CIA (filled circles), $\gamma$ HV68-CIA mice (open

251 squares), and ACRTA- $\mathrm{HV} 68 \mathrm{CIA}$ mice (open triangles); (B-I) Comparison of uninfected mice with

$252 \mathrm{CIA}$ (filled circles), $\mathrm{\gamma HV68-CIA}$ mice (filled squares), and ACRTA- $\mathrm{H}$ H68 CIA mice (filled triangles).

253 (B) Day (y-axis) of CIA onset, considered two consecutive scoring days of a score of at least 1, in

254 mice (x-axis) without $(\mathrm{CIA})$ and with latent $\gamma \mathrm{HV} 68$ infection $(\gamma \mathrm{HV} 68-\mathrm{CIA})$ or ACRTA- $\gamma \mathrm{HV} 68$

255 infection (ACRTA-pHV68 CIA). (C-I) Immune cell subsets determined by flow cytometry,

256 previously gates on lymphocytes, singlets, live cells, and $\mathrm{CD} 45^{+}$cells; (C) $\% \mathrm{CD} 3^{+} \mathrm{CD} 8^{+}$of $\mathrm{CD} 45^{+}$

257 cells in the spleen; (D) $\% \mathrm{CD}^{+} \mathrm{CD} 4^{+}$of $\mathrm{CD} 5^{+}$cells in the spleen; (E) $\% \mathrm{IFN} \gamma^{+}$of $\mathrm{CD} 8^{+}$cells in the 
spleen; (F) \%IFNy ${ }^{+}$of $\mathrm{CD}^{+}$cells in the spleen; (G) IL17 ${ }^{+}$of $\mathrm{CD}^{+}$cells in the spleen; (H) \%FoxP3 ${ }^{+}$

260 flow cytometry. (A-H) n=9-15 mice per group, 2 experiments, (I) n=5-9 mice per group, 1

261 experiment. (A-G) Each data point represents an individual mouse. Data presented as mean \pm

262 SEM. Analyzed by (A) two-way ANOVA with Geisser-Greenhouse's correction, (B-I) One-way

263 ANOVA, $* * * p<0.001, * * p<0.01, * p<0.05$, ns $=$ not significant.

266 As the number of ABCs are expanded in the contexts of both viral infection and autoimmunity,

267 including $\operatorname{RA}(25,28,29,33,35)$, we investigated the role of ABCs facilitating in viral enhancement 268 of $\mathrm{CIA}$. We began by examining the proportion and phenotype of ABCs in uninfected CIA mice 269 and $\mathrm{CIA}$ mice previously infected with latent $\gamma \mathrm{HV} 68(\gamma \mathrm{HV} 68-\mathrm{CIA})$ by flow cytometry (Figure 5 -

270 figure supplement $1 \mathrm{~A})$. We find that CIA induction increases the proportion and total number

271 of $\mathrm{ABCs}\left(\mathrm{CD} 19^{+} \mathrm{CD} 11 \mathrm{c}^{+} \mathrm{Tbet}^{+}\right)$in the spleen, and $\gamma \mathrm{HV} 68-\mathrm{CIA}$ mice have further increased

272 proportions of $A B C$ s in the spleen compared to $\mathrm{CIA}$ (Figure $5 \mathrm{~A}-\mathrm{B}$ ). The proportion of $\mathrm{ABCs}$ in the

273 ILNs is not a significantly different between $\gamma \mathrm{HV} 68-\mathrm{CIA}$ and $\mathrm{CIA}$ mice (Figure $\mathbf{5}$ - figure

274 supplement 1 C). The number of $A B C$ s is substantially lower in the ILNs than in the spleen,

275 concurring with other studies that find $\mathrm{ABC}$ s primarily reside in the spleen(36). During $\mathrm{CIA}$ and

$276 \gamma \mathrm{HV} 68-\mathrm{ClA}$, infecting mice at 6-8 weeks of age, we do not observe differences in the proportions

277 of $A B C s$ between male and female mice (Figure 5 - figure supplement $1 B$ ). 
279 We next examined the phenotypic characteristics and find that ABCs in the spleen are

280 phenotypically distinct in $\gamma \mathrm{HV68}-\mathrm{CIA}$ compared to CIA. First, fewer ABCs in the spleens of

$281 \gamma \mathrm{HV68-CIA}$ mice express IL10, while an increased proportion express IFN $\gamma$ (Figure 5C), indicating

282 that they are skewed towards a pathogenic Th1 phenotype. Further, fewer splenic ABCs in

$283 \gamma \mathrm{HV} 68-\mathrm{ClA}$ mice express inhibitory receptors CTLA4, PDL1, and PD1 (Figure 5D-F). This indicates

284 that $\mathrm{ABCs}$ in $\mathrm{CIA}$ mice play a more regulatory role than those in $\gamma \mathrm{HV} 68-\mathrm{CI} A$ mice. Additionally,

285 the $\mathrm{ABCs}$ in $\gamma \mathrm{HV} 68-\mathrm{ClA}$ mice display a more mature phenotype, with fewer $\operatorname{lgD}^{+} \operatorname{lgM}^{+}$naïve $\mathrm{B}$

286 cells and increased MHCII expression, though the expression of memory marker CD27 is

287 unchanged (Figure 5G-I). These results indicate that ABCs in $\gamma \mathrm{HV} 68-\mathrm{ClA}$ mice are more mature

288 and may have increased antigen presentation capacities but are not primarily a memory subset.

289 There are no differences in the expression of CD20, TNF $\alpha$, CD95 (Fas), nor IDO expression

290 (Figure 5 - figure supplement 1D-G). Collectively these results indicate that ABCs in $\gamma \mathrm{HV} 68-\mathrm{CI} A$

291 mice display a more pathogenic phenotype than those in $\mathrm{CIA}$, with decreased expression of

292 regulatory cytokine IL10 and inhibitory markers, and increased expression of IFN $\gamma$. 

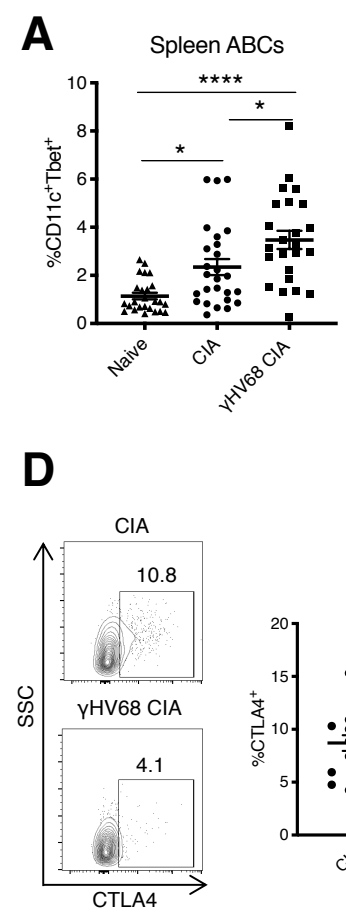

G

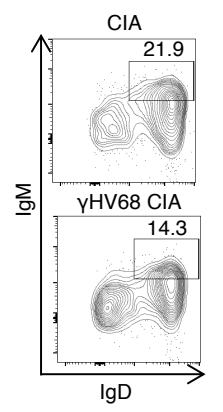

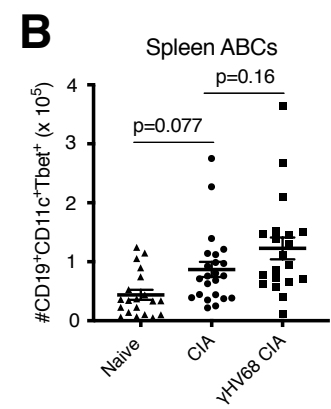

$\mathbf{E}$

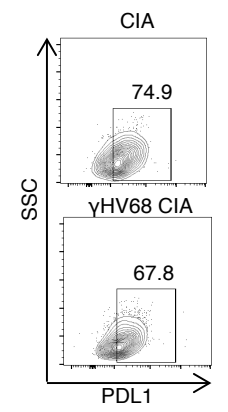

H
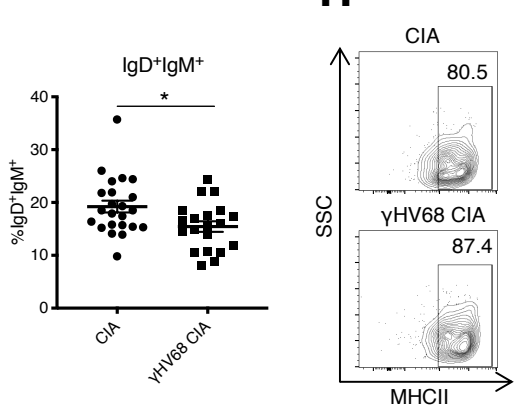
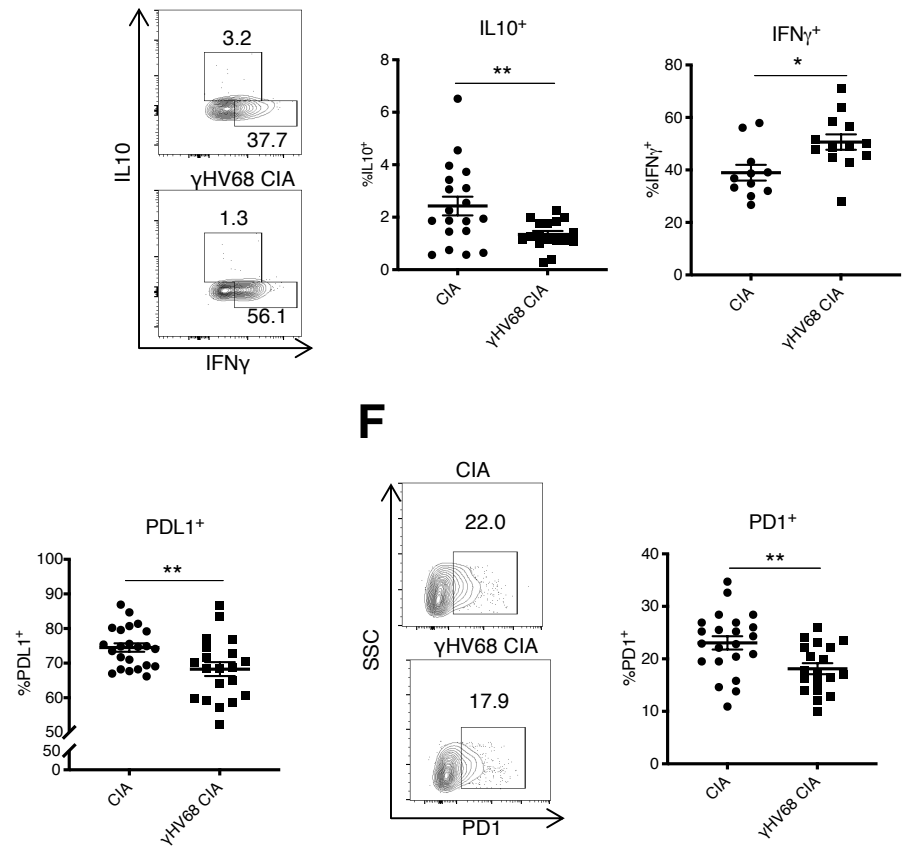

$\mathbf{F}$
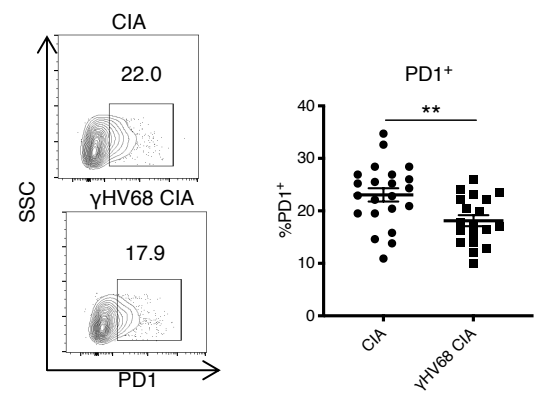

294

295

Figure 5: Analysis of $\mathrm{ABC}$ amount and phenotype by flow cytometry at 56 days post-CIA

induction. (A) Percentage of $A B C s\left(C D 11 c^{+}\right.$Tbet $\left.^{+}\right)$of mature $B$ cells (CD19+IgD $)$ in the spleen and

(B) total numbers of $A B C s$ in the spleen of naïve mice (filled triangle), uninfected mice with $\mathrm{ClA}$

298 (filled circles) and $\mathrm{HHV68-CIA}$ mice (filled squares). (C-I) Phenotype of ABCs analyzed by flow

299 cytometry. Previously gated on splenic $\mathrm{CD} 19^{+} \mathrm{CD} 11 \mathrm{c}^{+} \mathrm{Tbet}^{+} \mathrm{ABC}$. Flow plots are representative

300 samples, SSC = side scatter. Proportion of ABCs positive for (C) IL10 and IFNY, (D) CTLA4, (E)

301 PDL1, (F) PD1, (G) $\operatorname{lgD}^{+} \operatorname{IgM}^{+}$, (H) MHCII, (I) CD27. (A) n=24-26 mice per group, 3 experiments, (B) 
30323 mice per group, 2 experiments. (A-I) Each data point represents an individual mouse. Data

304 presented as mean \pm SEM. (A-B) Analyzed by one-way ANOVA, (C-I) Analyzed by t-test,

$305 * * * * \mathrm{p}<0.0001, * * * \mathrm{p}<0.001, * * \mathrm{p}<0.01, * \mathrm{p}<0.05$

308 To determine whether $\mathrm{ABCs}$ are a subset mediating the viral enhancement of $\mathrm{CIA}$ we utilized

309 ABC knock-out mice that harbor a B cell specific Tbet deletion. The clinical course and immune

310 profile of $\mathrm{CIA}$ and $\gamma \mathrm{HV} 68-\mathrm{CIA}$ mice was compared in littermate controls of Tbet ${ }^{\mathrm{fl} / \mathrm{fl}} \times \mathrm{CD} 19 \mathrm{Cre}^{+/-}$

311 (KO) and Tbet ${ }^{\mathrm{fl} / \mathrm{fl}} \times \mathrm{CD} 19 \mathrm{Cre}^{-/-}(\mathrm{Ctrl})$ mice (Figure 6A). We observe that the clinical course is

312 unchanged in $\mathrm{ClA}$ between $\mathrm{Ctrl}$ and $\mathrm{KO}$ mice, indicating that $\mathrm{ABCs}$ are not contributing to the

313 disease course in CIA (Figure 6B). Alternatively, when induced with CIA, $\gamma \mathrm{HV} 68$-infected KO

314 mice do not display the $\gamma \mathrm{HV} 68$-exacerbated clinical course compared to $\gamma \mathrm{HV} 68-\mathrm{ClA}$ Ctrl mice

315 (Figure $6 C$ ), indicating that $A B C s$ are a pathogenic subset in $\gamma \mathrm{HV} 680-\mathrm{CI}$. Without ABCs, $\gamma \mathrm{HV} 68-$

$316 \mathrm{CIA}$ mice do not display clinical exacerbation, but rather appear similar to uninfected CIA mice

317 in terms of disease severity and day of onset (Figure 6D-E). We observe that the ablation of

$318 \mathrm{ABCs}$ results in a decreased relative proportion of splenic $\mathrm{CD} 8^{+} \mathrm{T}$ cells in $\gamma \mathrm{HV} 68-\mathrm{ClA}$, though

319 there is no difference in relative proportion of $\mathrm{CD}^{+} \mathrm{T}$ cells (Figure $6 \mathrm{~F}-\mathbf{G}$ ). Relative proportion of

320 Tregs are slightly increased in KO mice in both $\mathrm{CIA}$ and $\gamma \mathrm{HV} 68-\mathrm{CIA}$ (Figure 6H). Expression of

321 IL17 or IFN $\gamma$ by $\mathrm{CD}^{+}$or $\mathrm{CD}^{+} \mathrm{T}$ cells is unchanged between Ctrl and KO groups (data not shown).

322 These results indicate that $\mathrm{ABC}$ s are important for coordinating the pathogenic $\mathrm{CD} 8^{+} \mathrm{T}$ cell

323 response and are a critical pathogenic population in $\gamma \mathrm{HV} 68-\mathrm{CIA}$. 


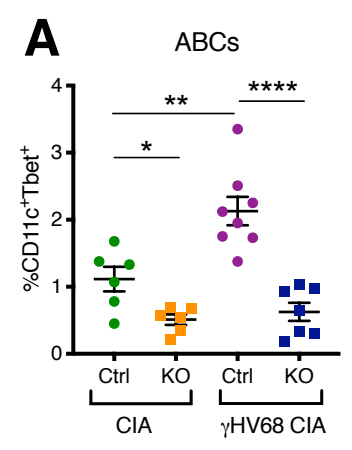

B

CIA

C $\quad \gamma H V 68 C$ CIA
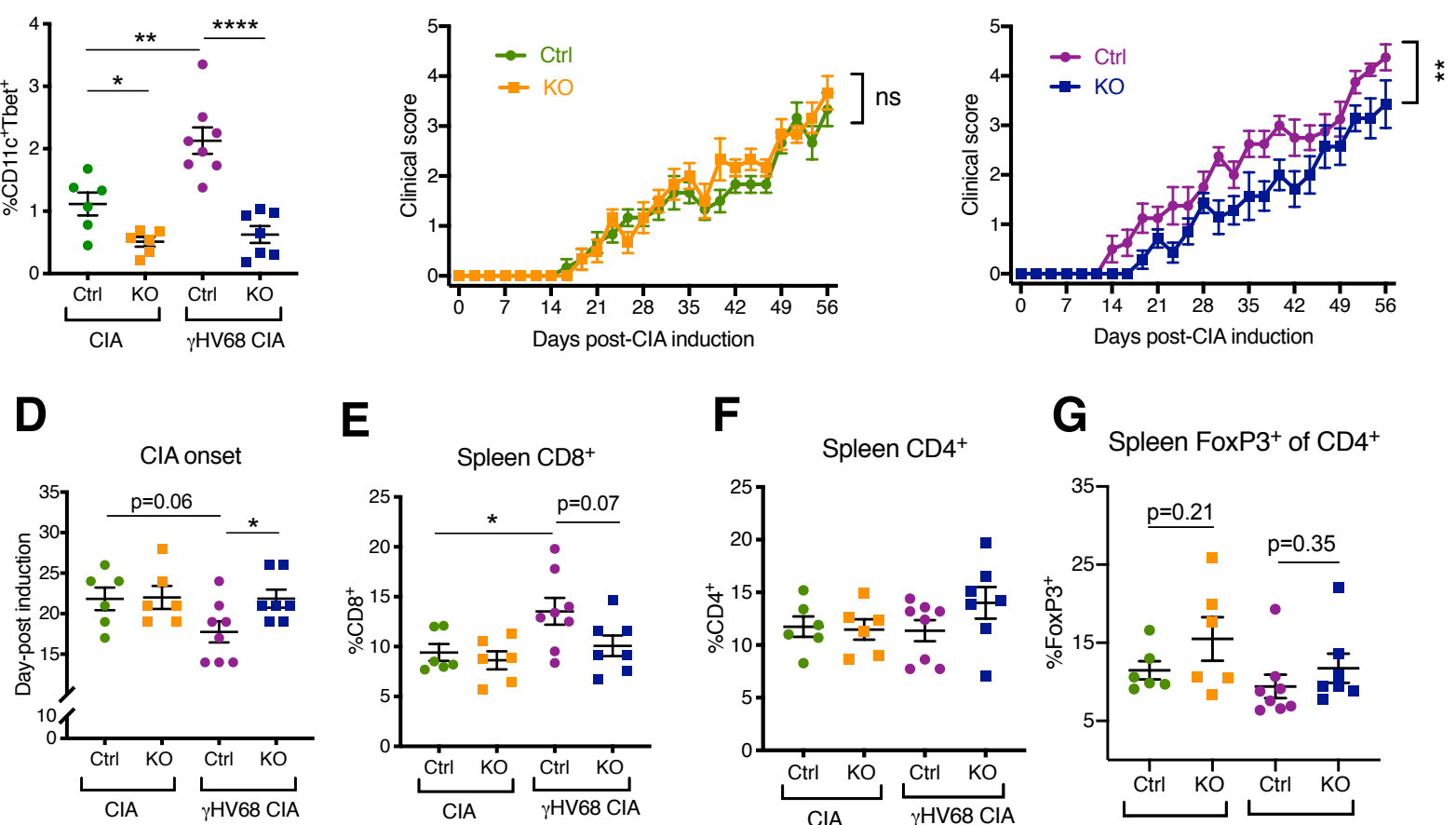

$\mathbf{E}$
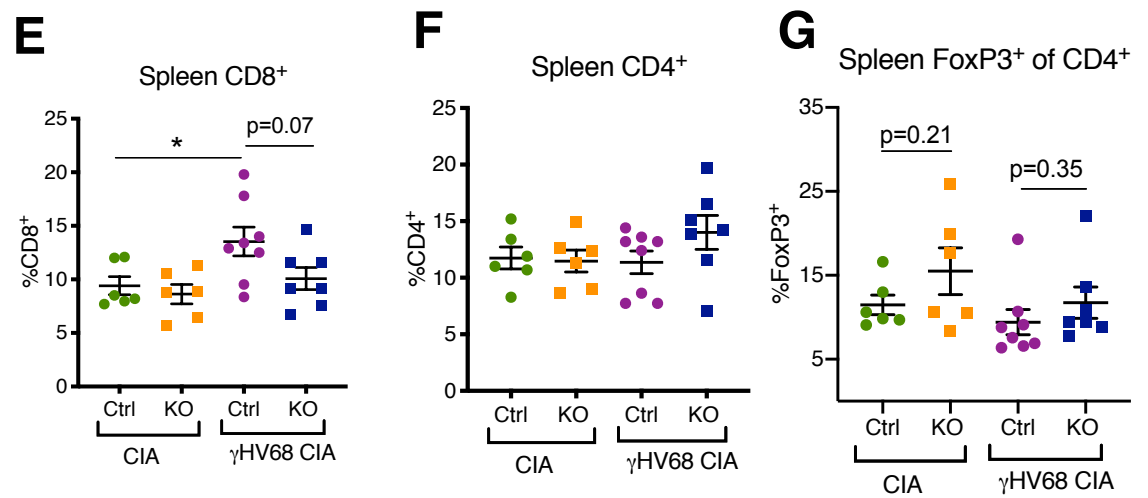

Figure 6: Disease progression and flow cytometric analysis of Tbet $^{\mathrm{fl} / \mathrm{fl}} \times \mathrm{CD} 19 \mathrm{Cre}^{+/-}$mice (KO)

compared Tbet ${ }^{\mathrm{fl} / \mathrm{fl}} \times \mathrm{CD} 19 \mathrm{Cre}^{-/-}$mice (Ctrl) that have been infected with $\mathrm{yHV68}$ or mock-

infected and induced for CIA. (A) Proportion of $A B C s\left(C D 11 c^{+}\right.$Tbet $\left.^{+}\right)$of mature $B$ cells

332 weekly for 8 weeks (x-axis; days) post CIA induction in Ctrl (green circles) and KO (orange

333 circles) mice that are uninfected with $\mathrm{CIA}$. (C) Clinical score (y-axis) of CIA measured three times

334 weekly for 8 weeks (x-axis; days) post CIA induction in Ctrl (purple circles) and KO (blue circles)

335 VHV68-infected CIA mice. (D) Day (y-axis) of CIA onset, considered two consecutive scoring days

336 of a score of at least 1 , in $\mathrm{Ctrl}$ and $\mathrm{KO} \mathrm{CIA}$ and $\mathrm{\gamma HV68-CIA}$ mice (x-axis). (E-G) T cells examined in

337 the spleen at day 56 post-induction by flow cytometry. Previously gated on lymphocytes, live 
338 cells, singlets, and $\mathrm{CD}_{4} 5^{+} \mathrm{CD}^{+}$cells. (E) $\% \mathrm{CD}^{+} \mathrm{CD}^{+}$of $\mathrm{CD} 45^{+}$, (F) $\% \mathrm{CD}^{+} \mathrm{CD} 4^{+}$of $\mathrm{CD} 45^{+}$, (G)

$339 \%$ FoxP3 ${ }^{+}$of $\mathrm{CD}^{+}$cells in the spleen. (A-G) $\mathrm{n}=6-8$ mice per group, 2 experiments. Data presented

340 as mean \pm SEM. Analyzed by (B-D) two-way ANOVA, (A, D-G) t-test, $* * * * p<0.0001, * * *$

$341 p<0.001, * * p<0.01, * p<0.05$.

343 Discussion

344 In this report, we demonstrate that latent $\gamma H$ V68 exacerbates CIA clinically and

345 immunologically, and Tbet $^{+} B$ cells, known as age-associated B cells, are critical for this

346 exacerbation. Investigation of the mechanism by which EBV contributes to RA has previously

347 been challenging due to the lack of a murine model to examine the systemic immune

348 modulation caused by latent gammaherpesvirus infection and resulting influence on arthritis.

349 Here, we show that infecting mice with latent $\gamma \mathrm{HV} 68$ prior to CIA induction results in an

350 immune course more similar to that of RA patients than CIA alone, and is a suitable model for

351 examining the contribution of EBV to RA. Elucidating how EBV infection contributes to the

352 development of RA is critical to understanding the underlying pathophysiology of the disease. 
354 As EBV is associated with several autoimmune diseases, it is important to examine whether

355 there are conserved mechanisms of contribution. The overlap in etiology and pathophysiology

356 between these autoimmune diseases may help to explain the cross-efficacy of

357 immunotherapies between MS and RA, including B cell depletion therapies. Our lab has

358 previously demonstrated that latent $\gamma \mathrm{HV} 68$ infection enhances EAE, a common model of MS,

359 clinically and immunologically(18). In both the $\gamma \mathrm{HV} 68-\mathrm{CIA}$ and $\gamma \mathrm{HV} 68-\mathrm{EAE}$ models we observe

360 an increase in $\mathrm{CD} 8^{+} \mathrm{T}$ cells at the site of disease and increased expression of IFN $\gamma$ by cytotoxic

361 and helper T cells. Latent gammaherpesvirus infection of mice clearly alters autoimmune

362 disease onset and severity reminiscent of the strong association of latent EBV infection in RA

363 patients. As such, these investigative models will serve to identify common mechanisms in

364 which EBV contributes to multiple autoimmune diseases.

366 Due to EBV infection often taking place years before the onset of arthritis, we posit that latent

367 EBV infection modulates the peripheral immune response in a manner that contributes to the

368 development of RA. We suggest that latently EBV-infected B cells alter, either directly or

369 indirectly, lymphocytes that go on to contribute to disease onset, likely through expanding and

370 activating $C D 8^{+} T$ cells and skewing towards a Th1 response. $C D 11 c^{+} C D 8^{+} D C s$ may play a role in

371 priming the pathogenic $\mathrm{CD}^{+} \mathrm{T}$ cell response, as they have been shown to cross-present

372 antigen $(47,48)$. By acting as a mediator between infected cells and pathogenic T cells, age-

373 associated B cells are likely critical moderators in driving the heightened Th1 immune response

374 to latent viral infection. 
376 Accumulating evidence shows that $A B C$ s are expanded in multiple autoimmune diseases and

377 function pathogenically in mouse models of lupus(25-32). Precisely how ABCs are contributing

378 to pathogenicity is unclear, and $A B C$ s are known to display multiple functional capacities that

379 could contribute to disease. In models of SLE, ABCs have been shown to secrete autoantibodies

380 and compromise germinal centre responses(30). Additionally, ABCs function as excellent

381 antigen-presenting cells(49). In a model of SLE, the ablation of ABCs decreases activated CD4 ${ }^{+} \mathrm{T}$

382 cells and IFN $\gamma-C D 8^{+} \mathrm{T}$ cells(32). How precisely $\mathrm{ABC}$ s are altering the $\mathrm{CD}^{+} \mathrm{T}$ cell population,

383 whether they are cross-presenting antigen or impacting the CD8 ${ }^{+} \mathrm{T}$ cells indirectly, warrants

384 further investigation. Alternatively, ABCs have been shown to secrete regulatory IL10(25,50),

385 suggesting that a portion of the $A B C$ population, or in some individuals or contexts, could

386 function in a protective manner. Further characterization of the phenotype and functional

387 capacities of $A B C s$ in autoimmune patients may help to elucidate their functional role. RA

388 patients who experience a relapse following B cell depletion therapy are more likely to display a

389 reconstitution profile with increased numbers of memory B cells(51). Whether existing

390 therapeutics, such as B cell depletion therapies or other approved drugs for RA, such as

391 Abatacept (CTLA4 Ig), impact the $A B C$ repertoire remains unknown.

393 Further evaluation of the influence of viral infection in $A B C$ pathogenicity is needed. It is

394 intriguing that $A B C s$ are pathogenic in a genetic model of SLE without the presence of a

395 virus(32), though we observe that latent $\gamma H \mathrm{HV} 68$ is necessary for the pathogenicity of $A B C^{\prime} s$ in

$396 \mathrm{CIA}$. This discrepancy indicates that $\mathrm{ABC}$ may be contributing to disease through various

397 mechanisms, or that different contexts can prime $A B C$ s for pathogenicity. The role of $A B C s$ in 
controlling viral infections is an ongoing topic of study, with multiple papers recently providing compelling evidence that $\mathrm{ABCs}$ are critical for an effective anti-influenza response(36) and are required to control of LCMV infection(52), in part through their secretion of antiviral IgG2a.

401 Additionally, the influence of aging on the $A B C$ population and influence on autoimmunity 402 development and progression warrants further study.

404 In summary, we have developed an in vivo model of EBV's contribution to RA that recapitulates 405 aspects of human disease. Further, we have examined the role of age-associated B cells and 406 find that they are critical mediators of the viral-enhancement of arthritis.

\section{Methods}

408 Mice

409 Tbet $^{\mathrm{fl} / \mathrm{fl}} \times \mathrm{CD} 19 \mathrm{Cre}{ }^{+/-}$mice were generated by crossing Tbet $^{\mathrm{fl} / f l} \times \mathrm{CD} 19 \mathrm{Cre}^{+/-}$and Tbet ${ }^{\mathrm{fl} / \mathrm{fl}} \mathrm{x}$

$410 \mathrm{CD} 19 \mathrm{Cre}^{-/-}$. Tbet $\mathrm{Tbl}^{\mathrm{fl} f}$ and CD19Cre ${ }^{+/-}$mice were provided by Dr. Pippa Marrack(32). C57BI/6 mice

411 were originally purchased from The Jackson Laboratory. All animals were bred and maintained

412 in the animal facility at the University of British Columbia. All animal work was performed per

413 regulations of the Canadian Council for Animal Care (Protocols A17- 0105, A17-0184).

$416 \gamma \mathrm{HV} 68$ (WUMS strain, purchased from ATCC) and ACRTA- $\gamma \mathrm{HV} 68$ (originally developed by Dr.

417 Ting-Ting Wu, the generous gift of Dr. Marcia A. Blackman)(53), were propagated in Baby

418 Hamster Kidney (BHK, ATCC) cells. Prior to infection, viruses were diluted in Minimum Essential 
419 Media (MEM, Gibco) and maintained on ice. Mice (6- to 8-week-old) were infected

420 intraperitoneally (i.p.) with $10^{4}$ PFU of $\gamma \mathrm{HV} 68$ or ACRTA- $\gamma \mathrm{HV} 68$ or mock-infected with MEM. No

421 clinical symptoms were observed from viral infections.

422

423 Induction of $\mathrm{ClA}$

424 On day 35 post-infection, CIA was induced by injection of immunization-grade, chick type II 425 collagen emulsified in complete Freund's adjuvant (CFA, Chondrex, Inc.) intradermally at the

426 base of the tail, followed by a booster injection of the same emulsion on day 14, as adapted

427 from(54). Each mouse received $0.1 \mathrm{mg}$ chick type II collagen and $0.25 \mathrm{mg}$ CFA at day 0 and 14.

429 Evaluation of CIA severity

430 Clinical signs of $\mathrm{CIA}$ were assessed and scored three times per week beginning at the day of CIA

431 induction: 0 = no symptoms, 1 = slight swelling and/or erythema, 2 = pronounced swelling and

432 erythema, 3 = severe swelling, erythema, ankylosis, as adapted from(55). Hind paws were

433 scored individually by a blinded scorer and added for a single score. Day of onset considered

434 two consecutive scoring days of a score of at least 1. The thickness of each hind paw was

435 measured using a digital caliper and the size was expressed as the average thickness of the two

436 paws.

438 Tissue harvesting and processing

439 Mice were anesthetised with isoflurane and euthanized by cardiac puncture. Blood was

440 collected by cardiac puncture into empty sterile tubes and placed on ice until processing, and 
441 mice were perfused with $20 \mathrm{ml}$ sterile PBS to allow for synovial fluid harvesting without blood

442 contamination. Inguinal lymph nodes (ILNs) and spleen were extracted and placed into $2 \mathrm{ml}$

443 sterile PBS and stored temporarily on ice until processing. Synovial fluid was collected by

444 exposing the knee and ankle joints, removing the patellar ligament, and flushing each flexed

445 ankle and knee joint with sterile RNase/DNase-free PBS (Invitrogen) using an 18-gauge needle,

446 adapted from(56,57). Using a $70 \mu \mathrm{m}$ cell strainer and a $3 \mathrm{ml}$ syringe insert, spleens and ILNs

447 were each mashed through the cell strainer mesh and a single-cell suspension was prepared for

448 each sample. Splenocytes were incubated in ACK lysing buffer for 10 minutes on ice to lyse red

449 blood cells and remaining cells were kept on ice until further use.

451 Flow cytometry analysis of cell-type specific surface antigens and intracellular cytokines

452 To evaluate cytokine production by various cell types, 4 million isolated splenocytes or inguinal

453 lymph node cells were stimulated ex vivo for 3 hours at $5 \% \mathrm{CO} 2$ at $37^{\circ} \mathrm{C}$ in Minimum Essential

454 Media (Gibco) containing 10\% fetal bovine serum (FBS, Sigma-Aldrich), $1 \mu \mathrm{l} / \mathrm{ml}$ GolgiPlug (BD

455 Biosciences), $10 \mathrm{ng} / \mathrm{ml}$ PMA (Sigma-Aldrich) and $500 \mathrm{ng} / \mathrm{ml}$ ionomycin (Thermo Fisher).

456 Stimulated cells were then washed prior to staining. For each spleen and ILN sample, 4 million

457 cells were stained in 2 wells, with 2 million cells per well. All collected synovial fluid cells were

458 resuspended in FACS buffer and stained in a single well. Before staining, samples were

459 incubated at $4^{\circ} \mathrm{C}$ covered from light for 30 minutes with $2 \mathrm{ul} / \mathrm{ml}$ Fixable Viability Dye eFluor506

460 (Thermo Fisher) while in FACS buffer (PBS with 2\% newborn calf serum, Sigma-Aldrich). Cells

461 were then incubated with a rat anti-mouse CD16/32 (Fc block) (BD Biosciences) antibody for 10

462 minutes. Fluorochrome labeled antibodies against cell surface antigens were then added to the 
463 cells for 30 minutes covered from light at $4^{\circ} \mathrm{C}$. After washing, cells were suspended in Fix/Perm

464 buffer (Thermo Fisher) for 30 minutes-12 hours covered from light at $4^{\circ} \mathrm{C}$, washed twice with

465 Perm buffer, and incubated 40 minutes with antibodies for intracellular antigens in Perm

466 buffer. Cells were then washed and resuspended in FACS buffer with 2 mM EDTA. Cells were

467 stained with anti-mouse CD45 (Clone 30-F11, Thermo Fisher Scientific), CD3 (Clone eBio500A2,

468 Thermo Fisher Scientific), CD19 (Clone eBio1D3, Thermo Fisher Scientific), CD4 (Clone RM4-5,

469 Thermo Fisher Scientific), CD8 (Clone 53-6.7, Thermo Fisher Scientific), FoxP3 (Clone FJK-16S,

470 Thermo Fisher Scientific), IFN $\gamma$ (Clone XMG1.2, Thermo Fisher Scientific), IL17 (Clone TC11-

471 18H10.1, Thermo Fisher Scientific), IL10 (Clone JES5-16E3, Thermo Fisher Scientific), CD11C

472 (Clone 418, Thermo Fisher Scientific), Tbet (Clone eBio4B10, Thermo Fisher Scientific), CD11b

473 (Clone M1/70, Thermo Fisher Scientific), IgD (Clone 11-26c, Thermo Fisher Scientific), CTLA4

474 (Clone UC10-4B9, Thermo Fisher Scientific), PDL1 (Clone MIH5, Thermo Fisher Scientific), PD1

475 (Clone J43, Thermo Fisher Scientific), IgM (Clone RMM-1, BioLegend), MHCII (Clone

476 M5/114.15.2, BioLegend), CD27 (Clone LG.3A10, BioLegend), CD20 (Clone SA275A11,

477 BioLegend), TNFa (Clone MP6-XT22, BioLegend), CD95 (Clone SA367H8, BioLegend), and IDO

478 (Clone mIDO-48, Thermo Fisher Scientific). The entirety of each sample was collected on an

479 Attune NxT Flow Cytometer (Thermo Fisher) and analyzed with FlowJo software v10 (FlowJo

480 LLC). Full-minus-one (FMO) controls used for gating.

$482 \quad$ IL17 and IFN $\gamma$ qPCR

483 RNA was extracted from synovial fluid and inguinal lymph nodes with a Qiagen AllPrep

484 DNA/RNA Micro kit. cDNA was synthesized using Applied Biosystems High-Capacity cDNA 
485 Reverse Transcription Kit (Thermo Fisher). qPCR was performed using iQTM SYBR ${ }^{\circledR}$ Green supermix (Bio-Rad) on the Bio-Rad CFX96 Touch $^{\text {TM }}$ Real Time PCR Detection system. Primer sets

487 from Integrated DNA Technologies were IL17a 5'-GCT CCA GAA GGC CCT CAG-3' (forward) and

488 5'-AGC TTT CCC TCC GCA TTG-3' (reverse) and IFN $\gamma$ 5'-ACT GGC AAA AGG ATG GTG AC-3'

489 (forward) and 5'-TGA GCT CAT TGA ATG CTT GG-3' (reverse). Normalized to the ribosomal

490 housekeeping gene 18s 5'-GTAACCCGTTGAACCCCATT-3' (forward) and 5'-

491 CCATCCAATCGGTAGTAGCG-3' (reverse) and expression determined relative to control group.

\section{Statistics}

494 Data and statistical analyses were performed using GraphPad Prism software 8.4.2 (GraphPad

495 Software Inc.). Results are presented as mean \pm SEM. Statistical tests, significance ( $p$-value),

496 sample size ( $n$, number of mice per group) and number of experimental replicates are stated in

497 the figure legends. Statistical analyses included: two-way ANOVA with Geisser-Greenhouse's

498 correction, unpaired t-test with Welch's correction if standard deviations were significantly

499 different, or one-way ANOVA. P-values indicated by asterisks as follows:

$500 \quad p<0.001, * * p<0.01, * p<0.05$.

503 All work was approved by the Animal Care Committee (ACC) of the University of British

504 Columbia (Protocols A17- 0105, A17-0184). 
Author contributions

507 Experiments were conceived of and designed by ICM and MSH. Experiments conducted by ICM

508 and ZJM. Data analyzed by ICM. IS contributed materials and analysis tools, maintained the

509 mouse colony, and performed genotyping. Paper written by ICM, KLB, and MSH.

511 Acknowledgements

512 We are grateful to Dr. Philippa Marrack for providing Tbet ${ }^{\mathrm{fl} / \mathrm{fl}}$ and CD19Cre ${ }^{+/-}$mice and to Jessica

513 R. Allanach for advice and help preparing the manuscript. This research was supported in part

514 by the MSSC, CIHR, UBC, and JDRF.

517 1. Humphreys JH, Verstappen SMM, Hyrich KL, Chipping JR, Marshall T, Symmons DPM. The

518 incidence of rheumatoid arthritis in the UK: comparisons using the 2010 ACR/EULAR

519 classification criteria and the 1987 ACR classification criteria. Results from the Norfolk

520 Arthritis Register. Ann Rheum Dis. 2013;72(8):1315-1320. doi:10.1136/annrheumdis-2012-

$521 \quad 201960$

522 2. Firestein GS, McInnes IB. Immunopathogenesis of Rheumatoid Arthritis. Immunity.

523 2017;46(2):183-196. doi:10.1016/j.immuni.2017.02.006

524 3. Balandraud N, Meynard JB, Auger I, et al. Epstein-Barr virus load in the peripheral blood of

525 patients with rheumatoid arthritis: accurate quantification using real-time polymerase chain reaction. Arthritis Rheum. 2003;48(5):1223-1228. doi:10.1002/art.10933 
527 4. Ascherio A, Munger KL. Environmental risk factors for multiple sclerosis. Part I: the role of infection. Ann Neurol. 2007;61(4):288-299. doi:10.1002/ana.21117

5. Gross AJ, Hochberg D, Rand WM, Thorley-Lawson DA. EBV and systemic lupus erythematosus: a new perspective. J Immunol Baltim Md 1950. 2005;174(11):6599-6607.

6. Blaschke S, Schwarz G, Moneke D, Binder L, Muller G, Reuss-Borst M. Epstein-Barr virus infection in peripheral blood mononuclear cells, synovial fluid cells, and synovial membranes of patients with rheumatoid arthritis. J Rheumatol. 2000;27(4):866-873.

7. Ferrell PB, Aitcheson CT, Pearson GR, Tan EM. Seroepidemiological study of relationships between Epstein-Barr virus and rheumatoid arthritis. J Clin Invest. 1981;67(3):681-687.

8. Catalano MA, Carson DA, Slovin SF, Richman DD, Vaughan JH. Antibodies to Epstein-Barr doi:10.1172/JCl110083

9. Alspaugh MA, Henle G, Lennette ET, Henle W. Elevated levels of antibodies to Epstein-Barr virus-determined antigens in normal subjects and in patients with seropositive rheumatoid arthritis. Proc Natl Acad Sci U S A. 1979;76(11):5825-5828. virus antigens in sera and synovial fluids of patients with rheumatoid arthritis. J Clin Invest. $1981 ; 67(4): 1134-1140$. induced polypeptide (EBNA-2) in the sera of rheumatoid arthritic families. Br J Rheumatol. $1987 ; 26(3): 193-196$. 
11. Lünemann JD, Frey O, Eidner T, et al. Increased Frequency of EBV-Specific Effector Memory

CD8+ T Cells Correlates with Higher Viral Load in Rheumatoid Arthritis. J Immunol.

12. Takei M, Ishiwata T, Mitamura K, et al. Decreased expression of signaling lymphocyticactivation molecule-associated protein (SAP) transcripts in T cells from patients with rheumatoid arthritis. Int Immunol. 2001;13(4):559-565. doi:10.1093/intimm/13.4.559

13. Dowd JB, Palermo T, Brite J, McDade TW, Aiello A. Seroprevalence of Epstein-Barr Virus Infection in U.S. Children Ages 6-19, 2003-2010. PLoS ONE. 2013;8(5).

14. Fourcade G, Germi R, Guerber F, et al. Evolution of EBV seroprevalence and primary infection age in a French hospital and a city laboratory network, 2000-2016. PLoS ONE.

15. Alamanos Y, Voulgari PV, Drosos AA. Incidence and prevalence of rheumatoid arthritis, based on the 1987 American College of Rheumatology criteria: a systematic review. Semin

16. Kuwana Y, Takei M, Yajima M, et al. Epstein-Barr Virus Induces Erosive Arthritis in Arthritis Rheum. 2006;36(3):182-188. doi:10.1016/j.semarthrit.2006.08.006 Humanized Mice. PLOS ONE. 2011;6(10):e26630. doi:10.1371/journal.pone.0026630 herpesvirus 68 into inflamed joints of arthritic mice. Eur J Immunol. 2018;48(2):250-257. doi:10.1002/eji.201747048 
18. Casiraghi C, Shanina I, Cho S, Freeman ML, Blackman MA, Horwitz MS. Gammaherpesvirus Latency Accentuates EAE Pathogenesis: Relevance to Epstein-Barr Virus and Multiple Sclerosis. PLOS Pathog. 2012;8(5):e1002715. doi:10.1371/journal.ppat.1002715

19. Olivadoti M, Toth LA, Weinberg J, Opp MR. Murine gammaherpesvirus 68: a model for the study of Epstein-Barr virus infections and related diseases. Comp Med. 2007;57(1):44-50.

20. Wirtz T, Weber T, Kracker S, Sommermann T, Rajewsky K, Yasuda T. Mouse model for acute Epstein-Barr virus infection. Proc Natl Acad Sci U S A. 2016;113(48):13821-13826. doi:10.1073/pnas.1616574113

21. Inglis JJ, Criado G, Medghalchi M, et al. Collagen-induced arthritis in C57BL/6 mice is associated with a robust and sustained T-cell response to type II collagen. Arthritis Res Ther. 2007;9(5):R113. doi:10.1186/ar2319

22. Marston B, Palanichamy A, Anolik JH. B cells in the pathogenesis and treatment of rheumatoid arthritis. Curr Opin Rheumatol. 2010;22(3):307-315. Epstein-Barr virus and B lymphocytes: implications for infection, immunity, and disease. Immunol Res. 2014;58(2-3):268-276. doi:10.1007/s12026-014-8496-1 Cells in Rheumatoid Arthritis, Impact of B Cell Depletion Therapy, and Biomarkers of Response. PLOS ONE. 2015;10(6):e0128269. doi:10.1371/journal.pone.0128269 
25. Rubtsov AV, Rubtsova K, Fischer A, et al. Toll-like receptor 7 (TLR7)-driven accumulation of a novel CD11C+ B-cell population is important for the development of autoimmunity. Blood. 2011;118(5):1305-1315. doi:10.1182/blood-2011-01-331462

26. Thorarinsdottir K, Camponeschi A, Jonsson C, et al. CD21-/low B cells associate with joint damage in rheumatoid arthritis patients. Scand J Immunol. 2019;90(2):e12792. doi:10.1111/sji.12792

27. Wang Y, Lloyd KA, Melas I, et al. Rheumatoid arthritis patients display B-cell dysregulation already in the naïve repertoire consistent with defects in B-cell tolerance. Sci Rep.

28. Claes N, Fraussen J, Vanheusden M, et al. Age-Associated B Cells with Proinflammatory Characteristics Are Expanded in a Proportion of Multiple Sclerosis Patients. J Immunol Baltim Md 1950. 2016;197(12):4576-4583. doi:10.4049/jimmunol.1502448

29. Wang S, Wang J, Kumar V, et al. IL-21 drives expansion and plasma cell differentiation of autoreactive CD11c hi T-bet + B cells in SLE. Nat Commun. 2018;9(1):1758. doi:10.1038/s41467-018-03750-7

30. Zhang W, Zhang H, Liu S, et al. Excessive CD11c+Tbet+ B cells promote aberrant TFH 2019;116(37):18550-18560. doi:10.1073/pnas.1901340116 
605

606

607

608

609

610

31. Rakhmanov M, Keller B, Gutenberger S, et al. Circulating CD21low B cells in common variable immunodeficiency resemble tissue homing, innate-like B cells. Proc Natl Acad Sci U S A. 2009;106(32):13451-13456. doi:10.1073/pnas.0901984106

32. Rubtsova K, Rubtsov AV, Thurman JM, Mennona JM, Kappler JW, Marrack P. B cells expressing the transcription factor T-bet drive lupus-like autoimmunity. J Clin Invest. 2017;127(4):1392-1404. doi:10.1172/JCI91250

33. Rubtsova K, Rubtsov AV, Dyk LF van, Kappler JW, Marrack P. T-box transcription factor Tbet, a key player in a unique type of B-cell activation essential for effective viral clearance. Proc Natl Acad Sci. 2013;110(34):E3216-E3224. doi:10.1073/pnas.1312348110

34. Chang L-Y, Li Y, Kaplan DE. Hepatitis C viraemia reversibly maintains subset of antigenspecific T-bet+ tissue-like memory B cells. J Viral Hepat. 2017;24(5):389-396. doi:10.1111/jvh.12659

35. Knox JJ, Buggert M, Kardava L, et al. T-bet+ B cells are induced by human viral infections and dominate the HIV gp140 response. JCI Insight. 2017;2(8). doi:10.1172/jci.insight.92943

36. Johnson JL, Rosenthal RL, Knox JJ, et al. The Transcription Factor T-bet Resolves Memory B Cell Subsets with Distinct Tissue Distributions and Antibody Specificities in Mice and Humans. Immunity. April 2020. doi:10.1016/j.immuni.2020.03.020

37. Barton ES, Rajkarnikar S, Langston PK, Price MJ, Grayson JM. Gammaherpesvirus latency differentially impacts the generation of primary versus secondary memory CD8+ T cells during subsequent infection. J Virol. 2014;88(21):12740-12751. doi:10.1128/JVI.02106-14 
625 38. Yamada H, Nakashima Y, Okazaki $\mathrm{K}$, et al. Th1 but not Th17 cells predominate in the joints of patients with rheumatoid arthritis. Ann Rheum Dis. 2008;67(9):1299-1304.

39. Casiraghi C, Márquez AC, Shanina I, Horwitz MS. Latent virus infection upregulates CD40 expression facilitating enhanced autoimmunity in a model of multiple sclerosis. Sci Rep.

40. Tada Y, Ho A, Koh DR, Mak TW. Collagen-induced arthritis in CD4- or CD8-deficient mice: arthritis. J Immunol Baltim Md 1950. 1996;156(11):4520-4526.

41. Morgan ME, Sutmuller RPM, Witteveen HJ, et al. CD25+ cell depletion hastens the onset of severe disease in collagen-induced arthritis. Arthritis Rheum. 2003;48(5):1452-1460. doi:10.1002/art.11063

42. Morita T, Shima Y, Wing JB, Sakaguchi S, Ogata A, Kumanogoh A. The Proportion of Regulatory T Cells in Patients with Rheumatoid Arthritis: A Meta-Analysis. PloS One. an altered phenotype during systemic autoimmunity. Clin Transl Immunol. 2016;5(4):e67. doi:10.1038/cti.2016.8 
643 44. Shen H, Goodall JC, Hill Gaston JS. Frequency and phenotype of peripheral blood Th17 cells in ankylosing spondylitis and rheumatoid arthritis. Arthritis Rheum. 2009;60(6):1647-1656.

45. Nistala K, Adams S, Cambrook H, et al. Th17 plasticity in human autoimmune arthritis is driven by the inflammatory environment. Proc Natl Acad Sci U S A. 2010;107(33):14751-

46. Rickabaugh TM, Brown HJ, Martinez-Guzman D, et al. Generation of a latency-deficient gammaherpesvirus that is protective against secondary infection. J Virol.

47. den Haan JMM, Lehar SM, Bevan MJ. Cd8+ but Not Cd8- Dendritic Cells Cross-Prime 2004;78(17):9215-9223. doi:10.1128/JVI.78.17.9215-9223.2004

48. Schulz O, Reis e Sousa C. Cross-presentation of cell-associated antigens by CD8alpha+ Cytotoxic T Cells in Vivo. J Exp Med. 2000;192(12):1685-1696.

49. Rubtsov AV, Rubtsova K, Kappler JW, Jacobelli J, Friedman RS, Marrack P. CD11c-Expressing dendritic cells is attributable to their ability to internalize dead cells. Immunology. 2002;107(2):183-189. doi:10.1046/j.1365-2567.2002.01513.x to innate stimuli accumulates in aged mice. Blood. 2011;118(5):1294-1304. 
663 51. Leandro MJ, Cambridge G, Ehrenstein MR, Edwards JCW. Reconstitution of peripheral blood

Rheum. 2006;54(2):613-620. doi:10.1002/art.21617

52. Barnett BE, Staupe RP, Odorizzi PM, et al. B cell intrinsic T-bet expression is required to control chronic viral infection. J Immunol Baltim Md 1950. 2016;197(4):1017-1022. doi:10.4049/jimmunol.1500368

53. Jia Q, Freeman ML, Yager EJ, et al. Induction of Protective Immunity against Murine Gammaherpesvirus 68 Infection in the Absence of Viral Latency. J Virol. 2010;84(5):2453-

54. Inglis JJ, Šimelyte E, McCann FE, Criado G, Williams RO. Protocol for the induction of 2465. doi:10.1128/JVI.01543-09

55. Brand DD, Latham KA, Rosloniec EF. Collagen-induced arthritis. Nat Protoc. 2007;2(5):1269arthritis in C57BL/6 mice. Nat Protoc. 2008;3(4):612-618. doi:10.1038/nprot.2008.19

56. Barton NJ, Stevens DA, Hughes JP, et al. Demonstration of a novel technique to quantitatively assess inflammatory mediators and cells in rat knee joints. J Inflamm Lond Engl. 2007;4:13. doi:10.1186/1476-9255-4-13 
A

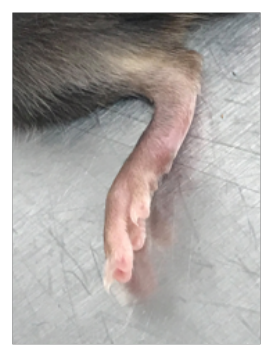

Score 1

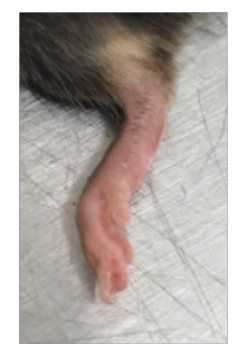

Score 2

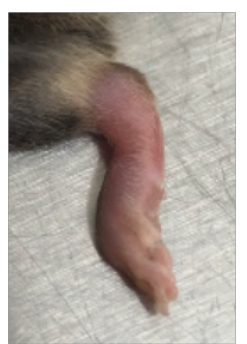

Score 3

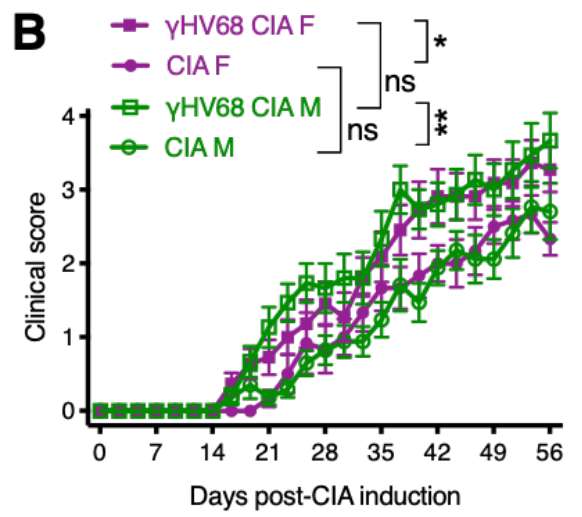

C

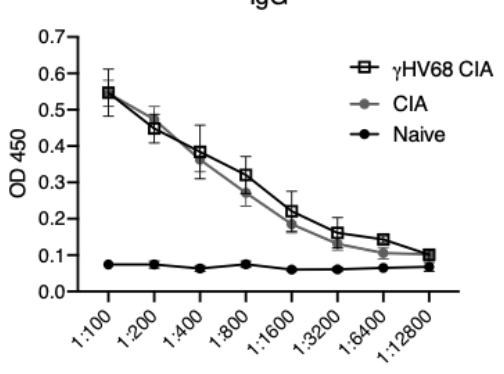

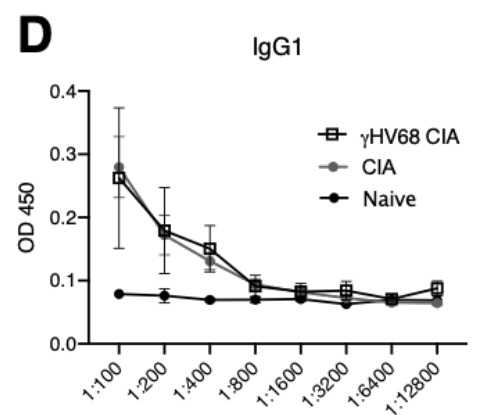

Serum dilution

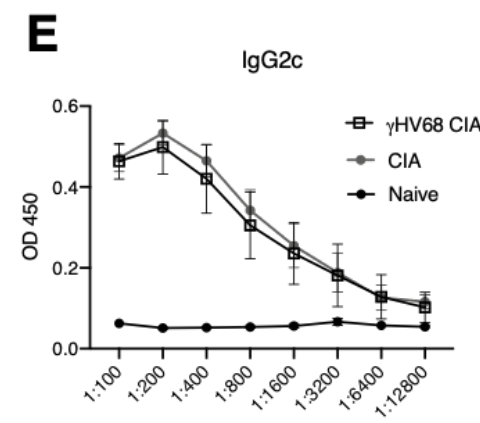

Serum dilution

684 Figure 1 - figure supplement 1: CIA paw scores and autoantibody titers. (A) Representative

685 photographs of paws with a corresponding CIA clinical score of 1, 2, and 3. (B) Clinical scores (yaxis) over the course of $\mathrm{CIA}$ ( $x$-axis, days post induction) in mice ( $n=11-17$ mice per group, same data as in Figure $1 \mathrm{~A})$ without $(\mathrm{CIA})$ and with ( $\mathrm{HHV68}-\mathrm{CIA})$ latent $\mathrm{\gamma HV68}$ infection, separated by sex. Data presented as mean \pm SEM and analyzed by two-way ANOVA. ns = not significant. (C-E)

691 circles), and $\mathrm{HHV68-CIA}$ (open squares) mice, $\mathrm{n}=3-4$ mice per group. Data presented as mean \pm SEM. 

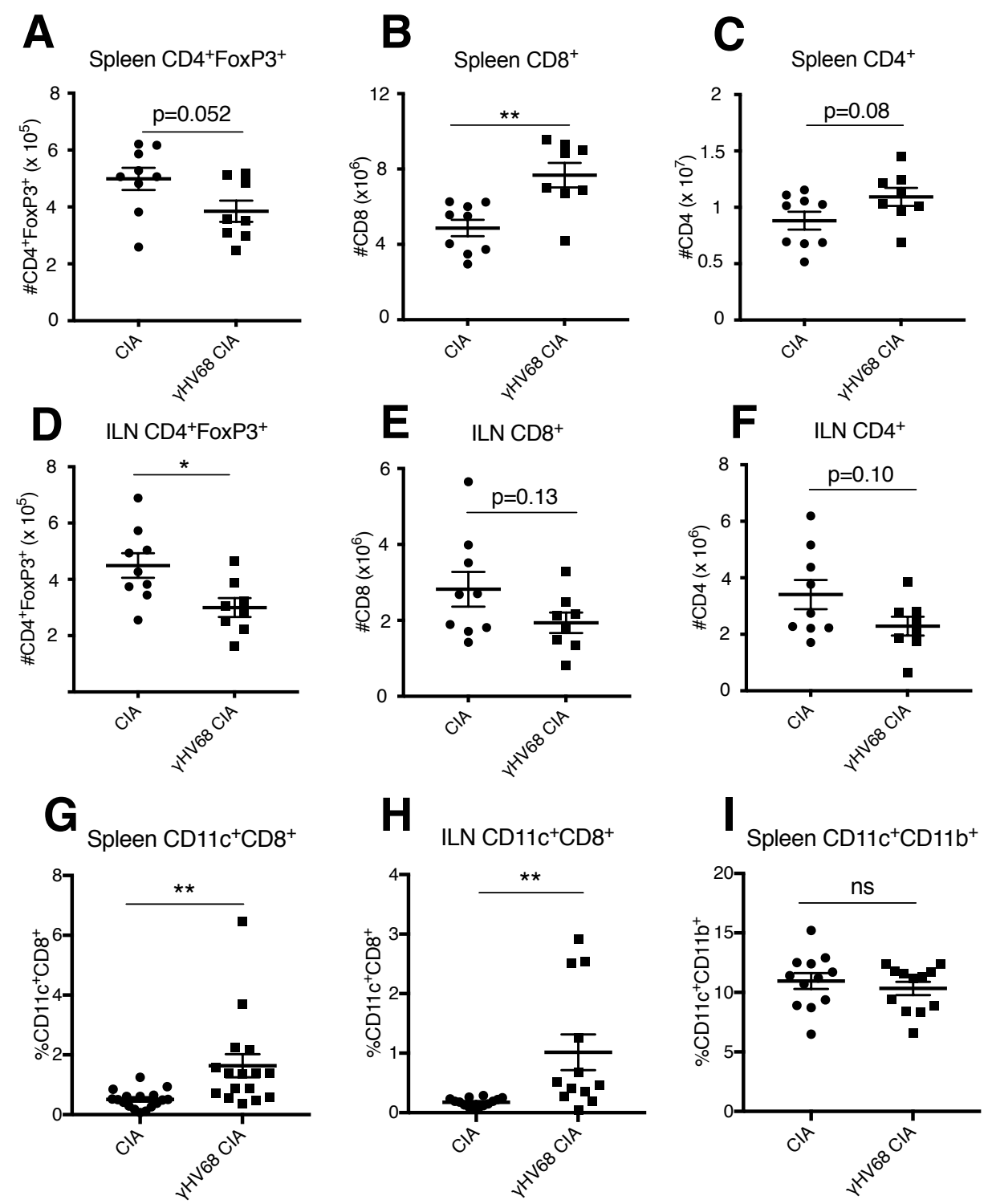

Figure 3 - figure supplement 1: Total numbers of spleen and inguinal lymph node T cell spleen and inguinal lymph nodes (ILN), as determined by flow cytometry in uninfected mice

698 with $\mathrm{ClA}$ (filled circles) and $\mathrm{yHV68-CIA}$ mice (filled squares). (A) Total number of CD4 ${ }^{+} \mathrm{FoxP}^{+}$

699 cells in spleen, (B) Total number of $\mathrm{CD}^{+} \mathrm{CD}^{+}$cells in spleen, (C) Total number of $\mathrm{CD} 3^{+} \mathrm{CD} 4^{+}$cells

700 in spleen. (D) Total number of $\mathrm{CD}^{+} \mathrm{FoxP}^{+}$cells in ILN, (E) Total number of $\mathrm{CD} 3^{+} \mathrm{CD} 8^{+}$cells in ILN,

701 (F) Total number of $\mathrm{CD}^{+} \mathrm{CD}^{+}$cells in ILN. Proportion of $\mathrm{CD} 11 \mathrm{C}^{+} \mathrm{CD} 8^{+}$cells of $\mathrm{CD}^{+} 5^{+} \mathrm{CD}^{-}$in the 
(G) spleen and (H) ILN. (I) Proportion of CD11 ${ }^{+} \mathrm{CD} 11 \mathrm{~b}^{+}$of $\mathrm{CD}^{2} 5^{+} \mathrm{CD} 19^{-} \mathrm{CD} 3^{-}$in the spleen. (A-F) $\mathrm{n}=8-9$ mice per group, 1 experiment, $(\mathbf{G}) \mathrm{n}=16-17$ mice per group, 3 experiments $(\mathbf{H}) \mathrm{n}=12-14$ mice per group, 2 experiments, (I) $n=12$ mice per group, 2 experiments. (A-I) Each data point represents an individual mouse. Data presented as mean $\pm \mathrm{SEM}$, analyzed by t-test, $* * \mathrm{p}<0.01$, $* \mathrm{p}<0.05, \mathrm{~ns}=$ not significant.
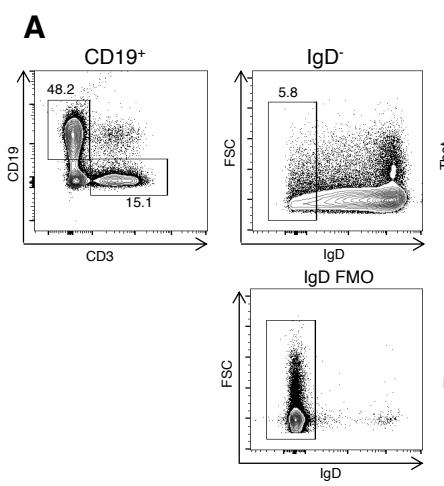

708

709

710

711

712

713

714

715

716

717
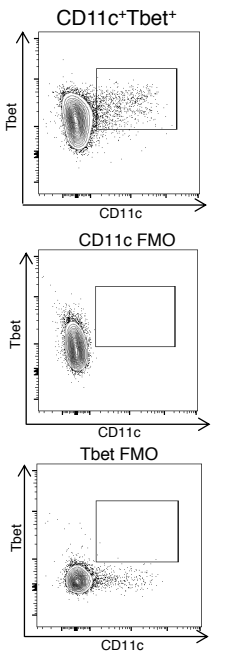

B
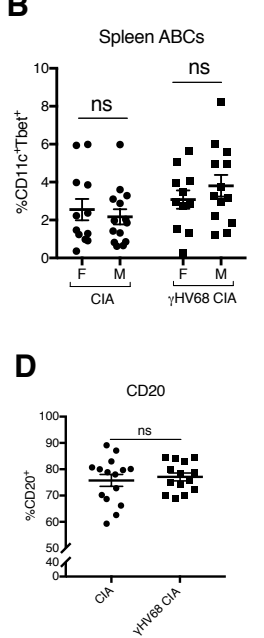

C

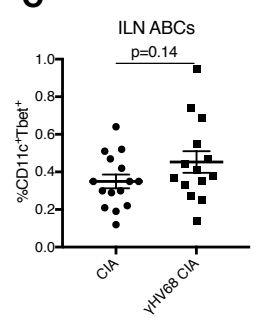

E

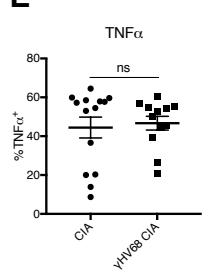

G

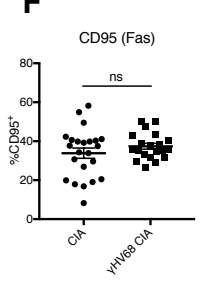

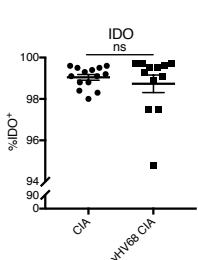

\section{Figure 5 - figure supplement 1: ABCs in the spleen analyzed by flow cytometry at 56 days}

post-CIA induction. (A) Representative gating strategy for $A B C s$ in the spleen using full-minus

one (FMO) controls. (B) Proportion of $A B C s\left(C D 11 c^{+}\right.$Tbet $\left.^{+}\right)$of mature $B$ cells $\left(C D 19^{+} I D^{-}\right)$in the

spleen of female (F) and male (M) mice in uninfected mice with CIA (filled circles) and $\mathrm{YHV68-}$

CIA mice (filled squares). Same results as figure 5A, separated by sex. (C) Proportion of ABCs

$\left(\mathrm{CD} 19^{+} \mathrm{CD} 11 \mathrm{c}^{+}\right)$of mature B cells (CD19+IgD') in the inguinal lymph nodes (ILNs). (D-F)

Proportion of $A B C$ s in the spleen expressing (D) CD20, (E) TNF $\alpha$, (F) CD95, and (G) IDO,

determined by flow cytometry. Previously gated on ABCs $\left(C D 19^{+} C D 11 c^{+}\right.$Tbet $\left.^{+}\right)$. (B) n=11-14 mice

per group, 3 experiments, (C) n=14-15 mice per group, 2 experiments, (D) $n=14-15$ mice per 
718 group, 2 experiments, $(\mathbf{E}, \mathbf{G}) \mathrm{n}=12-14$ mice per group, 2 experiments, $(\mathbf{F}) \mathrm{n}=20-23$ mice per

719 group, 2 experiments. (B-G) Each data point represents an individual mouse. Data presented as

720 mean \pm SEM. Analyzed by t-test $* * * * p<0.0001, * * * p<0.001, * * p<0.01, * p<0.05$, ns $=$ not

721 significant.

722

723 Supplementary methods

724 Anti-type II collagen antibody ELISA

725 The sera were isolated by centrifugation $2000 \times \mathrm{g}$ for $10 \mathrm{~min}$, aliquoted, and stored for up to 14

726 months at $-80^{\circ} \mathrm{C}$ prior to running the ELISA. Anti-type II collagen antibodies were quantified by

727 standard indirect ELISA. Briefly, ELISA plates (NUNC, Thermo Fisher) were coated with $5 \mu \mathrm{g} / \mathrm{ml}$

728 ELISA-grade type II collagen (Chondrex, Inc.) overnight at $4^{\circ} \mathrm{C}$, washed $4 \mathrm{x}$ with wash buffer (PBS,

$7290.05 \%$ Tween-20), blocked with 5\% newborn calf serum (NBCS, Sigma-Aldrich) for 1 hour at

$73037^{\circ} \mathrm{C}$, incubated with serial dilutions (1:100 to 1:12800) of test sera diluted in blocking buffer

731 for 2 hours at $37^{\circ} \mathrm{C}$, and washed $4 x$ wash buffer. Bound (anti-collagen II) antibody was

732 incubated with HRP-conjugated goat anti-mouse IgG (Thermo Fisher), rat anti-mouse IgG1 (BD

733 Biosciences), or goat anti-mouse IgG2c (Thermo Fisher), all diluted 1:500 in blocking buffer, for

7341 hour at $37^{\circ} \mathrm{C}$, washed $4 \mathrm{x}$ with wash buffer, and detected by TMB substrate (BD Biosciences).

735 Absorbance was read at $450 \mathrm{~nm}$ on a VarioSkan Plate Reader (Thermo Fisher). 